\title{
La forja de una comunidad entre Pamplona y Navarra. El copatronato de san Fermín y de san Francisco Javier (siglos XV-XVII)*
}

\author{
Alfredo Floristán Imízcoz \\ Universidad de Alcalá \\ Alfredo.floristan@uah.es
}

RESUMEN: El reino de Navarra conquistado e incorporado a Castilla (1512-1515) no invocaba a un patrón celestial común, y sus ciudades y pueblos vivían cómodas con sus santos particulares. Elaborar una identidad comunitaria en este punto - lo mismo que acerca del primer poblador, o sobre el primer rey-que, además, distinguiera al reino de los navarros entre los miembros primogénitos de la Monarquía de España, necesitó un largo proceso de decantación y polémicas. Se sucedieron y combinaron alternativas diversas: un mártir bien documentado de la primitiva Galia (Saturnino), su misterioso primer discípulo pamplonés (Fermín), y un navarro canonizado en 1622 (Francisco de Javier). Al final, en 1657, se llegó a un consenso forjado entre la ciudad capital y las instituciones del reino, que ha resultado más identitario, y duradero, que Túbal como patriarca o que García Jiménez como primer rey.
PAlabras Clave: identidades colectivas; santos; patronos; S. Satur- nino; S. Fermín; S. Francisco Javier; Pamplona; Navarra.

\footnotetext{
* Este trabajo ha sido realizado gracias al proyecto «Conformar la monarquía hispánica. Cultura política y prácticas dinásticas en los siglos XVI y XVII» (HAR2016-76214-P: MINECO), adscrito a la Universidad de Alcalá, dirigido por la Dra. Alicia Esteban.

Siglas utilizadas para los archivos: AHN (Archivo Histórico Nacional, Madrid); ARCR (Archivo de la Real Colegiata de Roncesvalles, Roncesvalles); ARGN (Archivo Real y General de Navarra, Pamplona); BNE (Biblioteca Nacional de España, Madrid); BCP (Biblioteca de la Catedral de Pamplona, Pamplona).

1 ORCID iD: https://orcid.org/0000-0003-1757-1427. 
Forging a community between Pamplona and Navarre. The joint patronage of Saint Fermín and Saint Francisco Javier (fifteenth-seventeenth centuries)

ABSTRACT: The conquered kingdom of Navarre incorporated into Castile (1512-1515) did not invoke a common celestial patron, and individual towns and villages were comfortable with their own particular saints. A protracted and contentious dispute process was needed to forge a common identity on this issue, in the same way that it was necessary to determine the first settler, or first king, especially if the Navarrese wished to distinguish their kingdom as a first-born member of the Monarchy of Spain. A succession of different alternatives and combinations were adopted: a well-documented martyr of primitive Gaul (Saturnino), his mysterious first disciple of Pamplona (Fermin) and a canonized Navarrese (Francisco de Javier). In the end, in 1657, a consensus was reached between the capital and the kingdom's institutions, which proved more identitary and permanent than Túbal as patriarch and García Jiménez as first king.

KEY WORDS: collective identities patron saints; St Saturnino; St Fermín; St Francisco Javier; Pamplona; Navarre.

CÓMO CITAR ESTE ARTÍCULO/CITATION: Floristán Imízcoz, Alfredo, «La forja de una comunidad entre Pamplona y Navarra. El copatronato de san Fermín y de san Francisco Javier (siglos XV-XVII)», Hispania, 80/266 (Madrid, 2020): xxx-xxx. https://doi. org/10.3989/hispania.2020.022.

En el siglo XV, los pamploneses, como los tudelanos, los estelleses, etc., no sentían la necesidad de un protector celestial común para todos ellos como navarros. Durante siglos, se habían manejado de forma muy flexible con una constelación de santos y de advocaciones particulares. La fama popular de santidad, la memoria de sus milagros y la devoción de una comunidad mantenida durante un tiempo bastaban para generar advocaciones de santos particulares, sin un proceso canónico regulado ${ }^{2}$. Tampoco los reyes o la nobleza navarra habían llegado a vincularse con claridad a ningún santo en particular. Carlos II Evreux dedicó a san Esteban la capilla que reformó como funeraria para su dinastía en la catedral; y Carlos III, «el Noble», fundó dos órdenes de caballería, la de La Bonne Foi y la del Lebrel Blanco, sin relación a un santo ni otro fundamento que el ornato y la emulación con las cortes de sus parientes en Francia. La orden castellana de Santiago (s. XII) y la aragonesa de San Jorge de Alfama (1201) tenían un contenido antiguo y real, y recordaban el perfil aristocrático-militar y reconquistador de ambos santos. Cuando los navarros hicieron memoria de sus dos grandes victorias, sobre los francos de

2 JIMENO, 2003. PÉREZ, 1947: 14-23. Sobre los santos medievales (Virila, Veremundo y Simeón); CHRISTIAN, 1991.

Hispania, 2020, vol. LXXX, n. ${ }^{\circ} 266$, septiembre-diciembre, págs. 817-850, ISSN: 0018-2141, e-ISSN: 1988-8368 https://doi.org/10.3989/hispania.2020.022 
Carlomagno en Roncesvalles y sobre los musulmanes de Abderramán I en Olast (Roncal), nunca las relacionaron con una ayuda celestial. El voto de Santiago que pagaban muchos campesinos del Norte de Castilla y de Portugal se suponía que era un reconocimiento del rey Ramiro I por su ayuda en la batalla de Clavijo (844). Y los reyes y nobles aragoneses agradecieron a san Jorge su auxilio en la batalla de Alcoraz (1096) y en la reconquista de Hueca designándolo como patrono, lo mismo que los catalanes recordaban su asistencia en la recuperación de Barcelona ${ }^{3}$.

Al igual que con sus santos patronos particulares, las comunidades locales vivían cómodas con sus fueros propios, y la aceptación de un Fuero General para toda Navarra en el siglo XV, que terminaría por asimilarlos o suplantarlos, avanzó despacio y suscitó resistencias. Desde ambas perspectivas, se estaba forjando una comunidad socio-cultural más amplia y compleja que la mera yuxtaposición de las precedentes. Ahora bien, una auténtica respublica navarrorum necesitaba dotarse de ligamentos nuevos, diferentes de los que habían articulado al mero regnum Navarra. Y uno de ellos fue la elección de un patrón general o «universal», que resultó un proceso más disputado que en otras comunidades y, a la postre, aunque por otros motivos, el que más inequívocamente etiqueta hoy a Navarra en el mundo.

La elección de un santo protector para una comunidad territorial más orgánica que la mera yuxtaposición de las comunidades locales parece propio de los siglos XVI y XVII en nuestra península. Este proceso maduró en Navarra a lo largo del siglo XVI aunque no se completó hasta avanzado el XVII. Los alaveses designaron un patrón para su provincia en sus Juntas Generales de 1644, cuando los procuradores y el clero de las Hermandades designaron a uno de sus naturales, a san Prudencio, nacido en Armentia y discípulo del eremita san Saturio de Soria, que predicó entre los paganos de Calahorra y fue obispo de Tarazona y Burgo de Osma ${ }^{4}$. Los guipuzcoanos lo tuvieron muy fácil cuando su paisano san Ignacio fue canonizado en 1622: «La provincia de Guipúzcoa [...] no se halla hubiese tenido ni elegido patrón en universo hasta que la hizo del Patriarca San Ignacio de Loyola a los 22 de julio de 1624». Y las Juntas Generales del Señorío de Vizcaya, a propuesta del rector del colegio jesuita de Bilbao, acordaron lo mismo en $1680^{5}$. El reino de Portugal, que renegó del Santiago común con Castilla y pretendió «portuguesizar» su figura ya antes de la separación, parece que tampoco «tuvo ni veneró por patrón suyo en universo» a nadie hasta 1644, cuando sus Cortes acordaron «recibir y jurar [...] por su patrona a la Santísima Virgen Nuestra Señora de la Concepción», tras descartar otras propuestas; Lisboa estuvo mucho tiempo sin patrón, con devociones a

${ }^{3}$ REY, 1985. SERRANO, 2014. ANGUERA, 2010.

${ }^{4}$ Actas de las Juntas Generales de Álava, n. ${ }^{\circ} 644039$ (25 noviembre 1644).

5 AHN, Códices, n. ${ }^{\circ}$ 1290, ff. 38r-39v.

Hispania, 2020, vol. LXXX, n. ${ }^{\circ}$ 266, septiembre-diciembre, págs. 817-850, ISSN: 0018-2141, e-ISSN: 1988-8368 https://doi.org/10.3989/hispania.2020.022 
varios santos, hasta que eligieron «a san Antonio de Padua su hijo» ${ }^{6}$. Se trataba, en todos los casos, de una decisión política, que no siempre resultó pacífica cuando contradijo las elaboraciones culturales o los intereses y los sentimientos predominantes.

Aragón, Cataluña y Valencia sí que tenían a san Jorge como patrono antiguo de cada uno de estos territorios desde la Edad Media: «No obstante que tienen por patrón al apóstol Santiago, que lo es de toda España, tienen patrón principal a san Jorge, mártir de Capadocia, que ni es natural de ninguno de dichos reinos, ni ha sido condecorado con el título de primer apóstol, ni en ellos ni en parte ninguna de ellos plantó la fe», informó un jesuita pamplonés a mediados del siglo XVII. Y, como trataba de eliminar a san Fermín como rival de san Francisco Javier en la pugna por el patronato de Navarra, recordó que las ciudades capitales en la Corona de Aragón mantenían patronos particulares que no eran ni el primer obispo ni el primer evangelizador de la ciudad (caso de san Fermín en Pamplona). En definitiva, afirmó con rotundidad, «como la elección de patrón de un reino, provincia, ciudad, etc., es acto libre, hiciéronla cómo y cuando gustaron» 7 .

Esto originó disputas abiertas en unos casos, como en Castilla o en Navarra, mientras en otros predominó una transformación paulatina, quizás fruto de un consenso de fondo socio-cultural, como en Aragón. El reconocimiento socio-político de la santidad de ciertas personas en España durante el periodo de la reforma católica (siglos XVI-XVII), y de su proclamación formal, de sus fiestas y de toda su expresión artística y literaria han recibido una necesaria atención desde hace años, y la «fabricación» de la santidad o de ciertos santos, su éxito y su frustración, constituyen una pieza más del amplio puzzle de la historia cultural ${ }^{8}$. Aquí pretendemos contribuir a todo ello con un estudio sobre la elaboración político-social y cultural de un patronazgo «universal» en el pequeño reino de Navarra. En el tiempo de las grandes cortes monárquicas, y de la potenciación del sistema político basado en el patronazgo y el clientelismo de las monarquías de agregación, las comunidades políticas locales o territoriales de la Europa católica se debieron de cuestionar parecidas alternativas con respecto a sus patronos celestiales: mantenerlos o renovarlos o reforzarlos, si ya los tenían, o procurárselos por primera vez, si carecían de ellos?.

De un «patrón» celestial se esperaba protección en esta tierra e intercesión en el tribunal de Dios: era, a la vez, un padre y un abogado. Le avalaban como tal sus acciones probadas, o lo que se esperaba que hiciera en favor de la comunidad como conjunto, más que por sus miembros particulares. Y aunque se

\footnotetext{
${ }^{6}$ AHN, Códices, n. ${ }^{\circ}$ 1290, ff. 39r-v. MARQUES, 1991.

7 AHN, Códices, n. ${ }^{\circ}$ 1290, ff. 39r-40r. SERRANO, 40/1 (Salamanca, 2018): 75-123.

${ }^{8}$ SERRANO, 2010; 2016; 2018. VINCENT-CASSY, 2001; 2012a; 2019. WORCESTER, 2010.

9 GÓMEZ ZORRAQUINO, 2010.
} 
reiterara que «si lo eligieran [patrón] será su elección de gracia o devoción, y no de justicia», cuando hubo disputas al respecto, no se pudo evitar las comparaciones de méritos entre unos y otros: si era mártir o sólo confesor, si natural o forastero, si obispo o religioso, si de los primeros varones apostólicos y evangelizadores o santo reciente, etc. La «aceptación» de determinado patrón se hacía mediante voto religioso o juramento civil por la ciudad o por el reino, aunque no siempre de forma explícita. Todavía durante el siglo XVI muchos de los patronos lo eran por asentimiento general no controvertido, lo que favorecía la acumulación y los cambios. Todo se replanteó cuando, en 1630, un decreto de la Congregación de Ritos (Decretum pro patronis in posterum eligendis) impuso un procedimiento más garantista de entonces en adelante: debía elegirse por patrón a un santo de la iglesia universal, lo debían votar los representantes de la comunidad, lo corroboraba el clero y el obispo de la diócesis, y se aprobada en Roma. Y esto se complicó cuando la bula Pro observatione festorum, de Urbano VIII (1642) redujo la posibilidad de celebrar litúrgicamente, y como día no laborable, tan sólo a un patrón y no más ${ }^{10}$.

Un procedimiento más garantista e intervencionista para renovar o para dilucidar el patrono universal de la comunidad favoreció debates sobre cuestiones jurídicas y devocionales, que traslucían intereses sociales, materiales y de poder. El mejor conocido es el que se discutió en Castilla sobre si convenía o no incorporar a la carmelita Teresa de Ávila, proclamada santa en 1622, como copatrona de Castilla junto con el tradicional apóstol Santiago (1618, 1626$1627)^{11}$. Algunos autores han considerado que el debate fue muy revelador y decisivo para el desarrollo de identidades plurales en la España moderna, aunque otros, con no menos razones, argumentan lo contrario ${ }^{12}$. Algunos han limitado su relevancia a cuestiones parciales o marginales, como las disputas políticas cortesanas relacionadas con el valido Olivares, o los conflictos de poderes entre el rey y la iglesia ${ }^{13}$. En Aragón, al parecer, esto mismo no generó una polémica pública tan notable, aunque los cambios subterráneos no fuesen menores. La expansiva devoción a la Virgen del Pilar, sobre todo después del milagro de Calanda (1640), resultó imparable en el siglo XVII, aunque la inercia era anterior, de modo que no hubo resistencia a recibirla como patrona de Zaragoza en 1642 y de Aragón en las Cortes de 1678, aunque junto con los antiguos patronos de la ciudad y del reino, san Valero y santa Engracia en un caso, y san Jorge en el otro ${ }^{14}$.

\footnotetext{
10 SERRANO, 2018: 76-78.

11 REY, 67/136, (Madrid, 2015): 531-573; 2008, vol. 1: 227-245.

12 ROWE, 2011. MÁRQUEZ, 2004.

13 El ensayo de Ofelia Rey en este mismo monográfico. THOMPSON, 2008; 2017.

14 SERRANO, LXXIV (Madrid, 2014): 687-714; 2014. CANELLAS, 19-20 (Zaragoza, 1966-1967): 7-22. MARCO, 1999.
} 
Queda una tercera polémica pública sobre un patrono universal en la España del XVII, la referente al reino de Navarra y a su capital Pamplona. Su desarrollo jurídico-canónico y sus facetas devocionales-artísticas han sido reconstruidas con solidez ${ }^{15}$, pero no tanto los argumentos y el contexto cultural y político. El problema se planteó en 1622: ¿debía proclamarse como patrono único de Navarra al jesuita san Francisco de Javier, una figura nueva, de dimensiones universales y de plena actualidad, frustrando el largo ascenso de la más familiar, particular y anticuaria personalidad del obispo san Fermín? Si en Aragón resultó decisiva la fusión de los cabildos de la catedral de El Salvador y de la basílica de la Virgen del Pilar para superar anteriores disputas y rivalidades, en Navarra también una concordia, negociada entre Pamplona y la Diputación del reino, facilitó que Roma proclamara a ambos santos como patronos igualmente principales del reino. En Castilla, sin embargo, se abandonó pronto y sin reservas la propuesta de copatronato promovido por los reyes, y la figura tradicional de Santiago permaneció inamovible después de un breve e intenso debate, aunque no dejaran de estudiarse otras alternativas, siempre en vano ${ }^{16}$.

Pretendo reconstruir y explicar qué ocurrió en la ciudad de Pamplona y en el reino de Navarra entre los siglos XV y XVII con respecto al patronato de san Fermín y de san Francisco Javier, y entender qué nos puede decir esto sobre la constitución de aquella sociedad política, como un caso particular que confrontar con las vecinas de Castilla y de Aragón. Atenderé en mayor medida que a los elementos externos, a los discursos que dan sentido y estabilidad a estas identificaciones colectivas. Trabajamos con elaboraciones literarias, de textos que reflejan la cultura de un grupo de cronistas y publicistas que, lo mismo que otros autores de hagiografías o de relaciones de milagros o de reliquias, escribieron imbuidos de amor y lealtad a su «patria» local y a su «nación». Pero que, a la vez, participaban de una cultura común y conocían lo que escribían sus correspondientes en otras ciudades, provincias y reinos limítrofes para, según los casos, adaptar o refutar sus ideas.

\section{En Pamplona: de san Saturnino a San Fermín (Siglos XV-Xvi)}

En la ciudad bajomedieval había tres parroquias, la más antigua dedicada a san Saturnino o san Cernin (circa 1100), una advocación provenzal que recordaba a un mártir de Toulouse del siglo III y que importaron inmigrantes francos. Sin embargo, no sabemos de ninguna capilla ni templo de san Fermín hasta los siglos XIV-XV, como devoción a un misterioso saint Firmin, mártir en la región de Picardía. El obispo Pedro de París (1186) en favor de su catedral, y el rey

15 GOÑI, 1979-1987. ARRAIZA, 2002. FERNÁNDEZ, 2006.

16 REY, LXVII (Madrid, 2015): 531-573. VINCENT-CASSY, 2012 b. 
Carlos II para la parroquia de San Lorenzo (1386) trajeron sendas reliquias de este san Fermín, aunque su culto no descolló de inmediato. Utilizando una referencia antigua de que era natural de Pamplona, lo hicieron discípulo de san Saturnino de Toulouse y lo consideraron primer obispo de su ciudad natal ${ }^{17}$. La gravedad de sendos altercados, en Pamplona en 1527, en torno a las imágenes de san Fermín que la catedral (cabildo) y la parroquia procesionaban con rivalidad mutua, y el hecho de que la antigua capilla del palacio tomara por entonces esta nueva advocación (1531), atestiguan un cambio ${ }^{18}$. De hecho, no sólo se enriqueció su bulto-relicario, prevaleciendo el de la parroquia sobre el de la catedral, sino que se elaboró un relato convincente, en el que un lejano e improbable san Fermín terminó por desbancar al más cercano e histórico san Saturnino ${ }^{19}$. Pero esto ocurría sólo en Pamplona y, aunque sendos sínodos diocesanos pretendieran extender su culto a toda la diócesis (1301: «Festum sancti Firmini colatur, et fiat cum octavis solenibus») no parece que prosperara de hecho ${ }^{20}$.

\section{La elaboración cronística y publicística de san Fermín (circa 1450-1607)}

A mediados del siglo XV encontramos una elaboración madura y muy peculiar en cuanto al modo como se conciben los orígenes del cristianismo navarro en comparación con el aragonés. Primero, porque lo vinculan con la diócesis francesa de Toulouse y, en particular, por una total ausencia del componente martirial. En Navarra no hubo memoria de martirios de época romana, ni reliquias, ni enterramientos, ni santos que puedan compararse con los de Zaragoza, o los de tantas otras ciudades españolas. Por otra parte, la labor misionera de san Fermín se concibió orientada hacia Francia y no hacia el resto de España. Sin duda, los navarros mantenían una vigorosa vinculación ultrapirenaica, también dinástica en su realeza desde 1234, aunque quizás esta no sea una explicación suficiente.

El relato más autorizado y antiguo sobre san Saturnino y san Fermín se lo debemos a Carlos de Aragón, Príncipe de Viana, autor de una Crónica de los reyes de Navarra (circa 1450) ${ }^{21}$. Cuando narra la cristianización del país, presenta a «sant Cerní» como primer evangelizador de Pamplona, de Navarra e, incluso, de España. Y menciona a san Fermín como un joven discípulo aventajado: nada dice de su futura condición de obispo o de mártir. El Príncipe de Viana desborda la austera Passio del santo, que se conocía desde antiguo, y

17 ARRAIZA, 2002. DUBOIS, 1971. GOÑI, 1979: 31-34; 1985: 195-197.

18 GOÑI, 1985: 195-197.

19 GARCÍA GAÍNZA, 1997: 93-94, 191-192.

20 «La fiesta de San Fermín es para adorar y se hace con la octava de la Solena», ARRAIZA, 2002: 73-75. GOÑI, 1979: 725-727. PÉREZ, 1947: 10-11.

${ }^{21}$ ORCÁSTEGUI, 1978: 78-79. 
adorna la dignidad episcopal y martirial de san Saturnino con los valores habituales en las hagiografías bajomedievales: lo esclarecido de su linaje (hijo del rey de Acaya y de la reina Casandra, hija de Tolomeo, rey de Nínive); su vinculación antigua y directa con Cristo (de los primeros discípulos de Juan el Bautista, del grupo de los setenta y dos enviados por Jesucristo, compañero de San Pedro en Antioquía y en Roma). El propio san Pedro lo envió a España, aunque se asentara en Toulouse y el primer contacto con Pamplona fuese a través de su capellán, Honesto.

Pero lo más significativo de su relato es el modo como entiende la evangelización de esta ciudad. Tres senadores, Firmus, Fortunatus y Faustinus, escucharon y aceptaron la predicación de Honesto, reclamándole que viniera en persona aquel que le había enviado, para que les «declarase los fechos de Ihesu Christo». Y entonces san Cernin vino a Pamplona desde Toulouse:

... y por los senadores fueron bien recibidos y, a la primera predicación que san Cernin hizo, convirtiéronse a la fe de Nuestro Señor, según dice su historia, XL mil personas o más ${ }^{22}$.

Lo relevante es la ausencia de resistencia violenta y la aceptación inmediata y masiva de la mera predicación, sin que se acompañase de milagros. San Saturnino y san Fermín encontraron resistencia y el martirio en Francia, pero no en Pamplona-Navarra. Según el Príncipe de Viana, su cristianización se habría producido de forma pacífica, temprana y kerigmática. «E plugo nos notar y escribir estas cosas porque a todos sea notorio ser mucho antiguo el tiempo de la conversión [...] a la fe christiana y llevar tanta ventaja este reino de Navarra a los otros reinos de España $\rangle^{23}$.

El licenciado Martín López de Reta, hacia 1580, retoma y desarrolla similares argumentos. Era un abogado imbuido del beligerante ambiente beamontés y navarrista que predominaba en los círculos eruditos de su ciudad ${ }^{24}$. En el Título que el autor dio al reino de Navarra y a la ciudad de Pamplona su cabeza $a^{25}$, reitera el tema de una cristianización rápida, masiva y pacífica, sólo en virtud de la predicación de san Saturnino: no hubo resistencias ni mártires. Él es el primero que explica este hecho excepcional como una predilección de Dios, que habría preservado a los navarros de entre todos los españoles «aún en la ley de la naturaleza»:

La mayor merced que Dios ha hecho a este reino es haberlo alumbrado con su fe católica luego que la promulgó, que en España fue la primera provincia que en

\footnotetext{
22 ORCÁSTEGUI, 1978: 79.

23 ORCÁSTEGUI, 1978: 79.

${ }^{24}$ FLORISTÁN, 1999; 2004: 327-354.

25 BNE, Manuscritos no 9329 , ff. $53 \mathrm{v}-62 \mathrm{v}$.
} 
universal recibió su fe católica [...]. Como los primeros progenitores y pobladores de este reino fueron los íberos, que con Túbal, hijo de Noé, vinieron a él, que era la gente más inclinada a la religión que entonces había, así lo fueron los descendientes de ellos ${ }^{26}$.

No pueden equipararse, prosigue, la «particular conversión de sólo nueve personas» que logró el apóstol Santiago entre Oviedo y Zaragoza, con la «universal» de Pamplona por la predicación de san Saturnino. Navarra sería manantial y reservorio incontaminado de cristiandad en España por una merced particular de Dios a este reino:

Y quedó en Navarra tan firme y cimentada y con tales raíces que nunca en este reino, después de que recibió la fe de Cristo, se halla haberla dejado ni apostatado de ella, ni aún entró herejía en él de la que a España han venido en diversos tiempos [arrianismo visigodo; islam], ni que por confesar la ley de Cristo martirizasen en este reino a nadie como hicieron en España en diversas partes y ciudades de ella, martirizando, persiguiendo y matando a muchos santos y siervos de Cristo por confesar su nombre ${ }^{27}$.

Y todo ello tendría que ver con que la fe llegara «no por quienquiera» sino por san Saturnino, discípulo del Bautista y compañero de san Pedro. En Reta, la cristianización sigue girando de forma preferente en torno a san Saturnino, mientras que san Fermín es, digamos, un subproducto: «De esta conversión [...] salió un grande santo mártir y obispo, que fue San Fermín» ${ }^{28}$.

Es probable que esta narración predominara entre las elites pamplonesas de aquellos años, porque coincide con lo que el canónigo Francisco Cruzat escribió hacia 1573 en un Catalogus episcoporum ecclesiae Pampilonensis ${ }^{29}$. Décadas después, el obispo y cronista Prudencio de Sandoval aprovechó a fondo este manuscrito para publicar su Catálogo de los obispos que ha tenido la Santa Iglesia de Pamplona (Pamplona, 1614), retocándolo y reinterpretándolo $^{30}$. Por eso, las versiones de Cruzat y de Sandoval se contradicen. El canónigo se alinea con Reta: aunque los pamploneses fuesen paganos, la mera predicación fue suficiente para su inmediata y masiva conversión, sin ninguna resistencia:

Reprehendió su ceguera, espantó y aún escandalizó la nueva doctrina, pero el buen natural de la gente de esta tierra, que Dios ya escogía para su rebaño, los alumbró de manera que hospedaron benignamente al nuevo predicador [...] Y

\footnotetext{
${ }^{26}$ FLORISTÁN, 1999: 174.

${ }^{27}$ FLORISTÁN, 1999: 176.

${ }^{28}$ FLORISTÁN, 1999: 175.

${ }^{29} \mathrm{BCP}$, Manuscritos $\mathrm{n}^{\circ} 143$

${ }^{30}$ GOÑI, 1985: 643-646; 1987, vol IV: 249-251.
} 
dentro de pocos días, Saturnino y Honesto vinieron a Pamplona donde, con su predicación y disposición que halló en los naturales, plantó y extendió la fe católica en Pamplona y su tierra ${ }^{31}$.

Sin embargo, el obispo-cronista, en su erudita presentación de las antigüedades romanas de Pamplona, plantea la hipótesis de que Santiago, de paso por Zaragoza, enviara a aquella gran ciudad a uno de sus discípulos a predicar el evangelio, que habría sido resistido allí como en tantas otras partes:

Sabemos de la multitud de mártires que hubo en Zaragoza, y otros tales habría en Pamplona, que era su vecina, y tantas y tan crueles las persecuciones que los emperadores romanos y los demonios con ellos movieron en aquellos tiempos contra la Iglesia ${ }^{32}$.

Sandoval quiso aportar pruebas, pero le faltaban las evidencias y sólo refiere una experiencia personal, muy imprecisa. Recuerda haber colocado en lugar decente, en el monasterio de san Jorge de Azuelo, con ocasión de su visita pastoral,

... un arca de roble antiquísima, llena de cabezas y huesos de mártires, y los hierros, saetas y cuchillos con que los habían martirizado, y en los huesos golpes crueles. [...] Fueron sin duda cuerpos de mártires que, cuando se perdió España, los escondieron allí3 ${ }^{33}$.

Por fin aparecían reliquias de mártires antiguos, pero demasiado tarde como para modificar la convicción secular de que en Navarra no hubo persecuciones ni, por lo tanto, mártires.

\section{Las guerras religiosas en Francia y la exaltación de san Fermín}

Fue durante la segunda mitad del siglo XVI cuando una recepción extraordinaria de reliquias de san Fermín y la elaboración de un relato-memoria de sus apariciones en favor de la ciudad, amalgamó a los pamploneses y sedujo a buena parte de los navarros.

No se trató de curaciones o de beneficios a particulares, por lo que sabemos, sino más bien de apariciones en favor de la seguridad y de la paz de Pamplona relatadas por sendos cronistas o publicistas. Martín López de Reta (circa 1580) coloca en el contexto de las guerras banderizas del siglo XV la más antigua

31 SANDOVAL, 1614: 5v.

32 SANDOVAL, 1614: 4v.

33 SANDOVAL, 1614: 5r. 
aparición de san Fermín: el santo protegió a los beamonteses de Pamplona del asalto traicionero que habían preparado sus rivales en 1471. El mariscal se concertó con un regidor agramontés, quien se ofreció para franquearle la puerta de la Zapatería y apoderarse de la ciudad en nombre de la princesa Leonor y, de paso, deshacerse de sus rivales beamonteses, con el condestable a la cabeza. Pero un mozo hornero dio la voz de alarma y don Felipe de Beaumont y los suyos estuvieron preparados:

Y arremetió a ellos con tanto ímpetu que enflaquecieron los enemigos, que iban retirándose vista la multitud que al encuentro les salió. Y en el mismo punto que esto sucedió decían los viejos de aquellos tiempos que apareció el glorioso san Fermín, hijo y protector de esta ciudad, vestido de blanco y rodeado de hachas encendidas, que puso tanto pavor que le cesaron muchas muertes más de las que sucedieron $^{34}$.

Según este relato probeamontés, san Fermín atenuó pero no evitó la violencia: murieron el mariscal y buena parte de sus agramonteses, y don Felipe de Beaumont «a los de la ciudad que pudo coger, mató, y a otros hicieron cuartos, y ahorcaron con las mismas sogas que llevaron los mismos enemigos $»^{35}$. Lo importante es que perduraba la memoria popular de lo ocurrido: en el nombre de «portal de la traición» de una de las puertas de la ciudad, y porque, junto a la capilla de San Fermín, pintaron la imagen del traidor, que se había escondido en una bodega,

... pusieron después pintado [...], sobre un tonel, con un letrero que estaba su nombre y decía: «Velifort». Este espectáculo se borró en mi tiempo [c. 1580], cuando de nuevo pintaron y doraron la dicha capilla del señor san Fermín y el sagrario que está junto a ella. Pusieron también sobre la capilla de este señor san Fermín el martillo y tenazas con que este regidor abrió la puerta (como hoy parecen), por insignias y memoria de la aparición de este santo ${ }^{36}$.

Con posterioridad, Urdániz (1649) y Sala (1650) recordaron la misma aparición, pero ya no en un contexto de violencia banderiza interna, sino como una muestra de fidelidad de la ciudad a la reina Leonor, y de pacificación cristiana entre las parcialidades ${ }^{37}$.

En 1515 se habría producido una segunda aparición de san Fermín: Ignacio de Andueza (1607), que no menciona la anterior, es el primero en relatarla, y de él la tomarán Urdániz (1649), Sala (1650) y Berdún (1693). En ella se refleja

\footnotetext{
${ }^{34}$ FLORISTÁN, 1999: 128, 125-129.

${ }^{35}$ FLORISTÁN, 1999: 128.

36 FLORISTÁN, 1999: 128-129.

37 URDÁNIZ, 1649. SALA, 1650.
} 
muy bien el vigoroso ambiente tridentino que dominaba la Pamplona de principios del siglo XVII. Un tal Cristóbal de Tabladillo, «capitán del carruaje de la católica majestad del rey de Navarra, que vivía en los palacios episcopales», habría sido despertado por san Fermín cuando dormía:

Oyó una voz muy temerosa que decía como llamando: «Cristóbal». A la cual voz recordando dijo: «¿Quién me llama?» Y le fue respondido: «San Fermín te llama». Y preguntando qué quería le dijo: «La voluntad de Dios es que por ti sea revelado y divulgado en la ciudad de Pamplona y reino de Navarra esto. Diles que Nuestro Señor está enojado contra ellos porque están muy dañados, y queriéndolos castigar con rigor se ha aplacado a suplicación de la Virgen Santa María y mía, y ha querido levantar la mano del castigo; y porque no le den ocasión a que los castigue, que hagan penitencia y que se enmienden; donde no, que a todos los destruirá. Esto divulgarás luego de mañana por toda la ciudad. Y dirás más, que en hacimiento de gracias a la Virgen María no coman carne los miércoles durante la penitencia» ${ }^{38}$.

Por tres noches consecutivas, del viernes 19 al domingo 21 de octubre de 1515, se repitió la voz y el mensaje, al que el propio Tabladillo no daba crédito y que no quiso divulgar. Sólo la aparición del santo, como un obispo revestido de pontifical y adorando a la Virgen, le convenció de comunicar la llamada a conversión a las autoridades eclesiásticas y civiles de Pamplona, que primero la acogieron con dudas, aunque luego aceptaran su veracidad. La visión no precisaba de qué pecados se trataba, y cuando se lo preguntaron, Cristóbal de Tabladillo tampoco supo qué responder, sino que cada uno debía arrepentirse de todo su mal. El relato resulta familiar a quien conozca la llamada de Samuel o la predicación de Jonás a los ninivitas, textos habituales en la liturgia católica y del dominio popular ${ }^{39}$.

En abril de 1572, poco antes de la muerte de Juana III de Navarre, la reina calvinista (junio), y de la matanza de hugonotes en la Noche de San Bartolomé (agosto), llegaron a Pamplona las principales reliquias modernas de san Fermín. Lo hicieron por mediación de don Francés de Álava, embajador de Felipe II en París, y a solicitud de su prima Beatriz de Beaumont y Navarra, de la casa de Arazuri, hija de un capitán de la guardia real y cofundadora del convento de Carmelitas Descalzas de la ciudad ${ }^{40}$. Lo notable fue cómo la ciudad recibió las reliquias el domingo 13 de abril de 1572, con solemnidad y fiestas extraordinarias, como nunca antes había ocurrido ${ }^{41}$.

Durante la guerra contra Enrique IV de Francia (y III de Navarre) llegaron más reliquias de san Fermín. En 1595, un sobrino del «doctor Navarro» Martín

\footnotetext{
38 ANDUEZA, 1656 [1607]: 140rv.

39 Samuel I, 3, 1-21. Jonás, 3-4.

40 RODRÍGUEZ, 1991.

${ }^{41}$ ANDUEZA, 1656 [1607]. ARRAIZA, 2002: 52-54.
} 
de Azpilcueta remitió la que había heredado de su tío, y, en marzo de 1597, se supo en Pamplona que el ejército de Felipe II había tomado Amiens. La Diputación, entonces, se animó a pedir al rey el traslado del cuerpo de san Fermín a Pamplona, como se había hecho con otras muchas santas reliquias «liberadas» de tierras de herejes ${ }^{42}$ :

Y considerando ahora ser todo de Vuestra Majestad, ha parecido a este reino suplicar, como lo hace por esta, sea servido de mandar escribir al señor Cardenal Archiduque pidiéndole ampare y esfuerce esta petición, de manera que se consiga este buen propósito de parte de la dicha ciudad de Pamplona ${ }^{43}$.

Aunque Enrique IV recuperó Amiens a los pocos meses, el capitán Martín de Olagüe, que protegió aquella catedral, consiguió del obispo una nueva reliquia de san Fermín para su pueblo natal.

Pero la figura de san Fermín adquirió su mayor relevancia social cuando Pamplona pidió al obispo trasladar su celebración litúrgica tradicional del 10 de octubre a la actual del 7 de julio. El sínodo diocesano de 1590 lo aceptó aunque careciera de fundamento litúrgico, porque tal fecha no tenía nada que ver con el santo: no era el día de su martirio ( 25 septiembre), ni el de su entrada en Amiens (10 octubre), ni el de la invención de sus reliquias (13 enero), que era lo que siempre se había celebrado. Pretendiendo una fiesta masiva y popular, convinieron una fecha que coincidiría siempre con las ferias de primeros de julio en Pamplona, «por ser tiempo más cómodo» para la asistencia y el regocijo ${ }^{44}$. Con ello se marcaron distancias respecto de la iglesia matriz de Amiens, que ha seguido celebrando a san Fermín el 10 de octubre, y se ligó al santo con la principal circunstancia socio-festiva de Pamplona y su ámbito de influencia.

El contexto favorecía el compromiso formal, mediante voto o juramento, de honrar a san Fermín como patrón. En la década de 1590, el «roi de Navarre», líder de los calvinistas de Francia y excomulgado por el papa, se había convertido en Enrique IV de Francia tras una abjuración de dudosa sinceridad y un perdón pontificio que muchos consideraban inmerecido o imprudente. Por entonces, los navarros se identificaron más bien con el católico Felipe II, que seguía empeñado en reimplantar la verdadera fe en Francia. San Fermín vino a ratificarles en su identidad como católicos, además de españoles, desde el momento en que luchaban para reponer el catolicismo en Francia, como san Fermín había muerto por darlo a conocer. Pero ni las autoridades de la ciudad ni las del reino llegaron a recibirlo como patrón de forma expresa hasta que, en 1599, llegó la peste a Navarra y amenazó Pamplona.

\footnotetext{
${ }^{42}$ FERRER, 2014.

43 ARGN, Reino: Actas de la Diputación, libro. 1, f. 16r.

${ }^{44}$ Constituciones synodales..., 1991, f. 115v.
} 
En ocasiones anteriores, los pamploneses habían recurrido a san Sebastián o a san Roque, y pronunciado votos solemnes a su favor, pero esta vez la ciudad se fijó en san Fermín. Nunca se le había asociado a la peste, pero sí había empezado a funcionar como protector particular de la ciudad, que es, en definitiva, lo que se esperaba de un patrón. Desde 1599, la procesión general de san Fermín por haberlos librado de la peste se convirtió en votiva y comunitaria, con participación universal del clero y del pueblo en sus corporaciones. Según la concordia de 1626, había cuatro votos escritos que comprometían a la ciudad: con san Sebastián, con san Roque, con san Fermín (1599) y con san Saturnino (1611), y otros cinco votos consuetudinarios (san Nicolás, santa Marta, santos Abdón y Senén, san Jorge, san Gregorio). Todos tenían que ver con la peste o la langosta, menos el último, el de san Saturnino, que vino a reforzar la figura de san Fermín de un modo más moderno, tridentino ${ }^{45}$.

En 1607, el vicario de San Lorenzo, Ignacio de Andueza, publicó una Vida y martirio de los santos patronos de la ciudad de Pamplona San Saturnino y San Fermín. Su identificación como patronos de la ciudad, en todo caso, era popular, informal y reciente; y, que sepamos, el reino nunca se había planteado la necesidad de contar con un patrón propio para todos los navarros. Pero Andueza logró volver a relacionar a ambos santos, aunque de un modo muy distinto a como lo había hecho el Príncipe de Viana a mediados del XV, y a proponerlos como patronos de Pamplona. Lamenta el olvido en que ha caído san Saturnino como primer apóstol y pretende remediarlo: «No es razón que este renombre tan singular esté sepultado, como lo ha estado, sino que salga a campear $\rangle^{46}$; y le parece que debiera celebrarse como fiesta de precepto, al igual que en Roma a san Pedro o en España a Santiago. Pero, en conjunto, Andueza se extiende más con san Fermín, fijando los rasgos del santo que han perdurado en la memoria popular hasta hoy: un pamplonés de familia consular pagana pero abierta a la nueva fe, catequizado y bautizado por san Saturnino, quien le consagró primer obispo de su ciudad natal donde permaneció por tres años, y que con 33 de vida, después de predicar a los gentiles en varias regiones de Francia, murió martirizado en Amiens.

Sabemos que el obispo Mateo de Burgos solicitó a la Congregación de Ritos, en 1606, aprobar un oficio propio de san Fermín en su diócesis de Pamplona y en el reino de Navarra — «Sanctus Firminus, episcopus et martir, filius patronusque civitatis pampilonensis ac totius regni Navarrae»-, pero nada más. Andueza había insistido en la importancia de san Saturnino como quien en verdad había erradicado los errores paganos y plantado la verdad de la fe, lo que, de acuerdo con la renovación tridentina, parecía de mayor relevancia que otros títulos de milagros, favores, apariciones, etc., comunes a tantos otros santos. Por eso, como acción de gracias y de acuerdo con el obispo y el cabildo, en 1611

${ }^{45}$ GOÑI, 1987, vol. V: 359-362.

46 ANDUEZA, 1656 [1607]: 83r, 82v-108r. 
el Regimiento de Pamplona hizo el voto de solemnizar su fiesta con procesión general, aunque no se le designó formalmente como patrón de la ciudad ${ }^{47}$.

\section{En Navarra: entre San Fermín y San Francisco JaVier (Siglo XViI)}

Quizás todo hubiera terminado aquí si un navarro reciente, de familia distinguida y miembro de la vigorosa Compañía de Jesús, no hubiera sido beatificado en 1619 y canonizado en 1622. San Francisco Javier no era un desconocido para sus compatriotas, pero sí una figura demasiado universal como para relacionarla de inmediato y popularmente con Navarra. Corrían muchas biografías suyas en Europa, pero sólo un canónigo de Roncesvalles, Juan de Huarte, había escrito sobre su vida, apostolado en oriente, prodigios y proceso de beatificación en Pamplona, aunque sin llegar a publicarlo $(1614)^{48}$. Los navarros sabían bastante poco de su paisano.

San Francisco Javier surgió como una alternativa moderna y muy específica a san Fermín, y esto originó un pleito y una polémica en la que muchos en el reino participaron con pasión. Todo se resolvió en 1657 mediante una concordia política que hizo a san Fermín y a san Francisco Javier patronos igualmente principales de Navarra, sin decir nada nuevo sobre Pamplona. Pero la resolución del pleito en Roma no debe engañarnos sobre el resultado real de la polémica. De inmediato, san Fermín resultó mejor asociado a la identidad colectiva del país y la figura de san Francisco Javier no se desarrolló de un modo similar hasta finales del XIX. Hoy, sin embargo, celebramos el día de la Comunidad Foral de Navarra el 3 de diciembre, y el 7 de julio es fiesta sólo en Pamplona.

\section{La polémica sobre el patronato del reino y su solución (1622-1657)}

La noticia de la beatificación de Francisco de Javier (25 de octubre de1619) se celebró de inmediato con fiestas costeadas por quien era entonces cabeza de su casa, Juan de Garro y Javier, vizconde de Zolina y pronto conde de Javier (1625), un eminente miembro del Brazo Militar ${ }^{49}$. Las Cortes de 1621 acordaron pedir a Felipe IV que el papa autorizara rezar «al beato padre [en Navarra] como se ha concedido en Portugal» y

... que la diputación, en nombre del reino, habiéndose concedido por Su Santidad la dicha licencia, lo reciba por su patrón, como a tan grande santo natural

47 NÚÑEZ, 1942: 34-36. GOÑI, 1987, vol. V: 360-361.

48 ARCR, Manuscritos, Juan de Huarte, Silva de lición y demostraciones de fidelidad, 1614.

49 FERNÁNDEZ, 2006: 32-40. 
de este reino y de tan ilustre familia, ofreciendo que el reino, en las primeras cortes generales, ratificará el dicho patronato con la solemnidad a tal acto conveniente $^{50}$.

La inmediata Diputación (1621-1624), de la que formó parte el vizconde de Zolina, hizo gestiones con el obispo y el cabildo de Pamplona, y ante los obispos de Zaragoza, Calahorra y Tarazona, con jurisdicción sobre algunos pueblos navarros, para que se le rezara en todo el reino. Pamplona celebró su canonización (12 de enero de 1622), pero el obispo y la ciudad se mostraron un tanto reticentes y no colaboraron con la Diputación, que organizó por su cuenta, en el colegio de los jesuitas, la ceremonia del juramento como patrón del reino a que se habían comprometido las últimas cortes ${ }^{51}$. Al final, el reino no le juró como patrón único o principal de Navarra el 2 de agosto de 1622 pero, aunque san Fermín nunca hubiera sido reconocido como tal, en Pamplona muchos debieron de sentir amenazada la preeminencia de su paisano, hasta entonces indiscutida.

Las inmediatas Cortes de 1624 acordaron celebrar su fiesta en el colegio de la Compañía con un gasto notable; obtener de los obispos con jurisdicción que se «le rezase con octava, como de patrón» en todo el reino; solicitar al Padre General el envío de «una reliquia» para el colegio; y que los Tres Estados ratificaran de inmediato, en la iglesia de la Compañía, el juramento como patrón del reino que la Diputación había adelantado en 1622. Pero algo ocurrió para que rectificaran de inmediato: el juramento para recibir a san Francisco Javier se retrasó al 11 de agosto y se trasladó a la catedral de Santa María ${ }^{52}$. En la misa de pontifical se leyó la ratificación del juramento adelantado por la Diputación en nombre de los Tres Estados dos años antes, al que todos asintieron colectivamente desde sus puestos, no individualmente, y lo recibieron por patrón y le prestaron «el juramento a tal acto decente $\rangle^{53}$.

La Diputación, en solitario, quiso solemnizar su fiesta ese mismo año, aunque con poco éxito, y parece que en Navarra apenas se obedeció la disposición del obispo de que se le rezara con octava y fiesta de precepto. Tampoco en el sínodo diocesano de 1634 dieron resultado los esfuerzos por implicar al clero y al obispo para que se le celebrara como a patrón, aunque así se indicara en las gallofas impresas, que colocaban a san Fermín como patrón de Pamplona. Por contraste - y quizás como reacción-, las celebraciones de san Fermín como «patrón» de Pamplona en 1628 resultaron extraordinariamente festivas y

${ }^{50}$ Actas de Cortes de Navarra, libro 2, n. 282 (Pamplona, 25 de febrero de 1621).

51 ARGN, Reino: Actas de la Diputación, libro II, ff. $17 \mathrm{v}-18 \mathrm{v}$.

${ }^{52}$ Actas de Cortes de Navarra, libro 2, n. 544 y 662 (Pamplona, 11 de julio y 8 de agosto de 1624).

${ }^{53}$ Actas de Cortes de Navarra, libro 2, n. 672 (Pamplona, 11 de agosto de 1624). FERNÁNDEZ, 2006: 40-44. 
populares (música en la catedral, gigantes, toros, toro de fuego, fuegos artificiales) e incluso se costeó una relación escrita para conservar y difundir su memoria ${ }^{54}$. Esto ocurría en un ambiente de fuertes tensiones particulares: entre el reino y la ciudad por alterar el sistema de gobierno de Pamplona; entre el obispo y el cabildo regular de la catedral por su reforma, y entre el obispo y el virrey por cuestiones regalistas. El telón de fondo eran problemas comunes de la Monarquía de España, porque a Navarra se le exigió un doloroso sobreesfuerzo militar y fiscal desde 1635, inusitado en aquella frontera hasta entonces. Todo ello favoreció un largo pleito sobre el patronato. Quizás, en circunstancias más normales todo se hubiera encauzado antes por el camino que se tomó cuando las aguas volvieron a su nivel.

El obispo Juan Queipo de Llano (1639-1647) dispuso en el nuevo libro de oficios propios de la diócesis (1642) celebrar a san Francisco Javier como patrón del reino y a san Fermín como patrón de Pamplona. Pero justo entonces se publicó el breve de Urbano VIII (13 septiembre 1642) sobre reducción de fiestas de precepto. El obispo tardó meses en publicarlo, pero ya en la fiesta de 1642 hubo incidentes en la celebración de san Francisco Javier y se evidenció el enfado del cabildo catedralicio, que se negó a ir a la iglesia de los jesuitas. La Diputación recordó al obispo el acuerdo del reino, pero este se resistió a autorizar una novedad que contrariaba a muchos y consultó con el nuncio, que remitió el asunto a Roma. En mayo de 1644, el obispo declaró a san Fermín patrón y abogado de toda su diócesis, y a san Saturnino patrón único de Pamplona; y quiso esperar a que Roma decidiera sobre quién lo sería del reino antes de ratificar la elección que habían hecho los Tres Estados. Las Cortes de 1645 y la subsiguiente Diputación reavivaron los esfuerzos e hicieron las primeras gestiones en Madrid y Roma con el apoyo de la Compañía de Jesús, sin que la ciudad de Pamplona se hubiera apenas movilizado todavía en favor de san Fermín ${ }^{55}$.

El pleito se precipitó cuando el nuevo obispo, Francisco de Alarcón y Covarrubias (1648-1657), aceptó y firmó la petición que había negado su predecesor, ratificando a san Francisco Javier como patrono del reino: «Fiat ut petitur». Más tarde argumentó que le habían engañado. Es probable que reaccionara así ante la, ahora ya, decidida oposición de la ciudad, del cabildo y del pueblo de Pamplona, quizás temerosos de que por ello perdieran relevancia las fiestas y ferias de san Fermín, que se celebraban «con mucho concurso de gentes circunvecinas». En definitiva, estaba en juego la siempre discutida posición de Pamplona como cabeza del reino y otros importantes intereses materiales y de poder. En 1649 la Diputación se lamentaba de la «indecencia» con que se hablaba de san Francisco Javier por las calles de la ciudad, y del

\footnotetext{
${ }^{54}$ GOÑI, 1987, vol. V: 383-384.

55 GOÑI, 1987, vol VI: 40-47. FERNÁNDEZ, 2006: 44-45.
} 
«menosprecio» con que se referían a los jesuitas, que se sentían acosados en público y se refugiaban en sus casas. Pero el del patronato no era el único ni, probablemente, el principal motivo de una amplia inquina contra la Compañía: la exención de diezmos de sus propiedades suscitó innumerables pleitos y generó un ambiente hostil. Hubo contactos, este mismo año, entre ambas partes y se planteó una composición similar a la que se adoptó al final. Pero mientras maduraba un ambiente de consenso, los agentes y abogados del cabildo, la ciudad y la Diputación maniobraban en Roma y en Madrid en favor de una u otra solución, y entre 1649 y 1652 los navarros debatieron públicamente el asunto ${ }^{56}$.

San Fermín contó con más impresos a su favor, y conocemos mejor los argumentos de quienes ensalzaron su figura y lo defendieron de ser arrumbado a un segundo plano ${ }^{57}$. Los defensores de san Francisco Javier, sin embargo, hicieron más bien una campaña de desprestigio del rival, lo que al final resultó contraproducente $^{58}$. Por otra parte, la Diputación y Pamplona se esforzaron, en 1650 , por sumar adhesiones escritas, formales, de las distintas corporaciones (pueblos, cabildos, monasterios) y también de fuera del reino (otras catedrales). Porque la Congregación de Ritos (23 de marzo de 1630) había dispuesto que la elección de patrón por parte de las comunidades civiles se hiciera mediante votaciones vecinales, ratificadas por el cabildo eclesiástico y el obispo, y aprobadas en última instancia por Roma.

Algunos de los poderes que recabó la Diputación de pueblos, cabildos y nobles con voto en cortes se expresaron, con más o menos claridad y energía, como actos de coherencia, o de obediencia, o de prudencia. No suelen ser muy explícitos. No argumentan apenas, sino que reiteran que ya juraron a san Francisco Javier en su momento, o que obedecerán lo que ordene el obispo, o que se sumarán a lo que decida la Diputación, sin más precisiones. Quizás la devoción sincera de Sangüesa se explique por su cercanía a Javier. Desde luego, en el caso de Tudela, la otra gran ciudad del reino, la rivalidad con Pamplona condicionó su «javierismo» más que cualquier otra consideración. Y la villa de Fitero apoyó a Pamplona (San Fermín) sólo por oponerse al abad del monasterio, su señor, que se había pronunciado al lado de la Diputación (san Francisco Javier). «Apóstol de la India, sol de oriente», «taumaturgo», «honor de este reino», su «naturaleza y patria» son los temas que más se repiten, pero que nunca llegan a desarrollarse en un argumentario tan rico como el que ya había madurado en favor de san Fermín ${ }^{59}$.

${ }^{56}$ GOÑI, 1987, vol VI: 133-143.

57 URDÁNIZ 1649. SALA 1650. ANDUEZA 1656 [1607].

58 Vida del glorioso San Fermín, AHN, Códices, n. 1290.

59 ARGN, Reino: Patronato y culto de San Fermín y San Francisco Javier, legs. 21-25 (1650). FERNÁNDEZ, 2006: 45-49, 82-84, 86-88. 


\section{Discursos ideológicos e identificaciones populares}

Miguel de Urdániz publicó, por encargo del cabildo parroquial de San Lorenzo, un Memorial (1649) dirigido a la ciudad en el que se hizo eco de la

... alteración que causó en los vecinos de esta ciudad cuando oyeron publicar la festividad de San Francisco Xavier con motivos de patrón del reino [1648], con que quedaron turbados sus corazones, haciendo demostraciones de sentimiento, estorbando semejante publicación, quizá todo con desagrado de los mismos santos ${ }^{60}$.

Este licenciado en derecho, abogado de las reales audiencias de la ciudad y de cierta erudición histórica, lo redactó con el propósito de movilizar y dar argumentos en favor de san Fermín. En un Consejo de Estado de 1645, ante los requerimientos de la Compañía y de la Diputación para que se hiciera efectiva la celebración de san Francisco Javier «como único patrón del reino», Felipe IV pidió información al virrey, conde de Oropesa. Este lo hizo favorablemente y el citado consejo propuso encargar al embajador en Roma esa gestión, «representándole el desconsuelo del reino de Navarra, y que sólo en él se podrá guardar esta fiesta ${ }^{61}$. El Memorial de Urdániz elabora la defensa de san Fermín como patrón de Navarra y también, de forma inseparable, una exaltación de Pamplona como epítome del reino y de sus grandezas, explicable en el ambiente de vigoroso navarrismo historiográfico predominante por entonces en el país ${ }^{62}$.

Si Urdániz defiende que san Fermín tiene más derecho que nadie para ser patrón único del reino, es, en primer lugar, porque ya ha cumplido con lo que se esperaba de un patronus según el derecho romano:

... si patrón se llama al que hace oficio de padre, que con sus auxilios y socorros libra de los peligros a otros y hace oficio de abogado, previniendo los riesgos, atajando los castigos, aliviando trabajos, curando enfermedades desahuciadas, procurando la paz de los suyos que vivan en la fe católica que abrazaron ${ }^{63}$.

Los romanos sabían de la conveniencia «de tener en la corte de su príncipe un protector y patrón para interceder por ellos». Y recuerda los favores obtenidos gracias a san Fermín en torno a su fiesta de 1632, recogidos en el «lienzo de los milagros» de su capilla, y las gracias de sus dos apariciones $(1471,1515)$. Por todo ello se veían obligados, en justicia, a mantenerlo y honrarlo como

\footnotetext{
${ }^{60}$ URDÁNIZ, 1649, Cuarto discurso, sin paginar.

${ }^{61}$ AGS, Estado, leg. 3850, exp. 83 (Agradezco la referencia a Roberto Quirós y a Tibor Martí).

${ }^{62}$ FLORISTÁN, 2004: 181-183, 225-233. Se identifica con la Historia apologética de García de Góngora, Pamplona, 1628.

${ }^{63}$ URDÁNIZ, 1649, Primer discurso, sin paginar.
} 
«nuestro hermano». Por otra parte, la predicación de san Fermín y san Saturnino había hecho a los navarros «libertos» de la servidumbre del error de la gentilidad, quedando en deuda perpetua con su libertador.

Trento había ratificado la doctrina canónica sobre los patronatos de laicos, que se justificaban en casos de «fundación, reedificación y posesión» de ciertas instituciones eclesiásticas ${ }^{64}$. Si los fundadores de las «religiones» eran patronos de las mismas - y nadie dudaba de que san Ignacio, y no otro, lo era de la Compañía de Jesús - «a santo que en nuestro reino no fundó ni predicó la fe convirtiendo sus naturales [san Francisco Javier], no le puede tocar ser patrón de este reino excluyendo a san Fermín, que tiene mejor derecho en este patronato» ${ }^{65}$. $\mathrm{Y}$ en esto se explaya Urdániz desarrollando un argumento muy vigoroso por entonces: el de la antigüedad con que arraigó la fe cristiana, la prontitud con que se aceptó y la fidelidad con la que siempre se había conservado. Todo ello tenía que ver con el discurso tubalista y cantabrista que había empezado a adaptarse como propio, también en el reino de Navarra, en el último cuarto del siglo $\mathrm{XVI}^{66}$ : «Nuestros antepasados progenitores cántabros, descendientes de Túbal», precisamente por serlo, habrían estado predispuestos para aceptar de inmediato la verdad del cristianismo y para no abandonarla jamás. La oración de san Fermín, poco antes de su martirio, en favor de preservar inconmovible la fe de los navarros, la compara con la de san Pedro en pro de la iglesia universal ${ }^{67}$.

Este gran argumento de Urdániz reitera y desarrolla lo que ya había publicado Ignacio de Andueza en 1607: que san Saturnino y san Fermín — las dos «columnas de la fe», como san Pedro y san Pablo — habrían sido «apóstoles de Navarra», donde no hubo "persecuciones del gentilismo y de la africana morisma y se conservó ilesa en la fe». En concreto, pretende justificar la falta de mártires, algo sorprendente y un tanto humillante durante siglos: en Pamplona no había memoria ni reliquias de época imperial, tan abundantes en Zaragoza, Ágreda o Calahorra. Y aunque Sandoval hubiese argumentado lo contrario (1614), Urdániz se reafirma en la convicción común:

... por más cierto tengo que en este reino de Navarra no martirizaron a ningún cristiano, siendo así que todos lo eran después que san Saturnino les predicó, porque nunca lo dejaron de serlo [...]. Y fueran tan sin número en esta ciudad y reino de Navarra los mártires, y más que en la ciudad de Zaragoza, si no les acobardara

${ }^{64}$ Concilio de Trento: Sesión XXV, «De reformanda Ecclesiae», cap. IX: «Cómo se ha de probar el derecho de patronato y a quién se deba dar» (1563).

${ }^{65}$ URDÁNIZ, 1649, Segundo discurso, sin paginar.

${ }^{66}$ FLORISTÁN, 2004: 340-344.

${ }^{67}$ URDÁNIZ, 1649, Cuarto discurso, sin paginar. Cita con frecuencia a Juan Gutiérrez, su Practicarum quaestionum civilium, en Opera omnia sex tomos divisa, Venecia, 1593, 1. ${ }^{\text {a }}$ ed. 
a los emperadores romanos el ver que tan copiosa multitud de gente y tan valerosa profesaban una religión que tan de corazón habían abrazado ${ }^{68}$.

Los navarros eran una «invencible nación» y por ello los romanos, «por conservarse en amistad con los navarros y los cántabros, por ser ella gente invencible, les dejaron vivir en la religión y fe que habían abrazado».

La fe sembrada por san Fermín habría dado frutos abundantes de santidad, principalmente en san Francisco Javier y también en otros apóstoles de las Indias, y de este modo presenta al rival como un santo subordinado y no singular. Y lo hace desde un providencialismo sin complejos, aunque poco original:

Fue presagio para la India y Nuevo Mundo que su conquista espiritual estaba reservada a los naturales de este reino, supuesto que la primera vez que se descubrieron por el almirante don Cristóbal Colón, fue día de san Fermín, en once de octubre del año $1491[\mathrm{sic}]^{69}$.

Pero, sobre todo, presenta al santo como eficaz defensor de la ciudad ante las amenazas de los franceses en 1638, con ocasión del asedio de Fuenterrabía. Por entonces, la ciudad trajo solemnemente, desde Olagüe, la reliquia de san Fermín que el capitán Miguel de Olagüe había recibido del obispo de Amiens en 1597, ya mencionada:

... que fue pronóstico cierto de la asistencia y protección que, ese mismo año, poco tiempo después de colocada esta santa reliquia en el pecho de la santa imagen, le tuvimos con la gran victoria y socorro de Fuenterrabía [...]. Y por tener esta ciudad y reino unas prendas tan grandes de este santo, tenemos con esto la mayor defensa y amparo del reino, y no por el presidio y murallas fuertes con que esta ciudad está adornada, teniendo por esto ser ella y el reino de Navarra llave de toda España [...], que es cierto que por estas grandes reliquias tenemos la mayor seguridad de nuestros enemigos, visibles e invisibles, y no por la esperanza de nuestras fuerzas humanas ${ }^{70}$.

En aquel momento, los navarros todavía no contaban con una reliquia de san Francisco Javier que pudiera protegerles.

El Memorial subraya, también, las diferencias de «un santo obispo mártir y apóstol del reino [san Fermín], a un confesor tan solamente [san Francisco Javier]», y que no sería «decente» echar al primero para colocar en su lugar al segundo. En buena medida, porque a san Fermín ya se le había considerado patrón del reino y había pruebas de ello, por lo que «no sería justo quitarle esta prerrogativa a nuestro santo». Pero, sobre todo, porque Urdániz defiende una

${ }^{68}$ URDÁNIZ, 1649, Cuarto discurso, sin paginar.

${ }^{69}$ URDÁNIZ, 1649, Cuarto discurso, sin paginar.

${ }^{70}$ URDÁNIZ, 1649, Cuarto discurso, sin paginar. 
estrecha identificación entre Pamplona y Navarra: «Diciendo Pamplona se dice todo el reino». Por eso, concluye, la ciudad debe defender con vigor el patronato de san Fermín para toda Navarra y no sólo para Pamplona, porque el acuerdo de las cortes en favor de san Francisco Javier no habría sido válido por varios motivos. Si los procuradores habían votado sin poderes especiales; si no habían considerado los méritos de ambos santos «en utilidad de su patria y nación»; si no habían previsto los «inconvenientes que podían resultar de algunas turbaciones en los corazones», no habría resultado válida la elección ${ }^{71}$.

En la misma imprenta, la mayor de Pamplona, se publicaron en 1650 unas Razones y autoridades con que se prueva que San Fermín es el patrón más principal del Reyno de Navarra, también dedicadas a la ciudad. El licenciado Juan de la Sala se presenta como vicario parroquial, no sabemos si de San Lorenzo, y escribe un auténtico alegato jurídico-canónico, más agresivo y mejor organizado que el Memorial de Urdániz, y avalado por abundantes citas de autoridades jurisdiccionales. En esencia, quiere probar: $10^{\circ}$ que en san Fermín concurren los requisitos idóneos para ser patrón; $2^{\circ}$ " «que efectivamente lo es por actos positivos, por posesión inmemorial y tradición antigua»; y $3 .^{\circ}$ «que la elección de patrón que hizo el reino en el glorioso san Francisco Javier no fue con los requisitos necesarios para su validación $»^{72}$.

La Sagrada Congregación de Ritos había confirmado (1630) que cualquier santo canonizado podía ser designado patrón por un lugar, ciudad o reino, aunque, «si lo eligieran, será su elección de gracia o devoción, y no de justicia». Y san Fermín le parece que reúne todas «las calidades y condiciones» para serlo: hijo de Pamplona, su primer obispo, predicador de la fe en ella y en todo el reino, por lo que es tenido por «apóstol de Navarra» y «vaso de elección» para difundir el evangelio ${ }^{73}$. Aunque Trento ${ }^{74}$, como dijimos, había confirmado con ciertas condiciones el patronato material de los laicos, Sala replantea estos decretos conciliares en términos de patronato espiritual. San Fermín habría tenido este derecho a ser patrón del reino «pues de gracia y elección divina se lo dio Dios, instituyéndolo por Apóstol y Vaso de Elección de Navarra»; y la fundación espiritual de esta iglesia la considera «más excelente, legítima y verdadera que la material de que tratan los autores» $\rangle^{75}$. Por otra parte, ya había ejercido como tal patrón («qui aliquem in periculo defendit») cuando se apareció a los pamploneses en 1471 y en 1515 para mantener la paz y la concordia, o cuando les defendió de las pestes $(1348,1401,1599)$. Sala repasa las decisiones del obispo Juan Queipo de Llano, e interpreta que su intención en 1647 fue

${ }^{71}$ URDÁNIZ, 1649, Cuarto discurso, sin paginar.

72 SALA, 1650, Presentación, sin paginar.

73 SALA, 1650, «Punto primero»: n. ${ }^{\circ} 8$.

${ }^{74}$ Concilio de Trento: Sesión XXV, De reformanda Ecclesiae, capítulo IX (1563).

75 SALA, 1650, «Punto segundo»: n. ${ }^{\circ}$ 10, 13. 
declarar a san Fermín como patrón del reino entero, a la espera de la sentencia de la Congregación de Ritos. Y aduce diversos testimonios que avalarían una, dice, «tradición antigua», aunque fuese muy reciente: entre otros, el libro de Andueza (1607), un memorial del cardenal Zapata como obispo de Pamplona (1606), las armas del reino impresas en las estampas del santo con que los cuestores pedían limosna ${ }^{76}$.

A la hora de refutar las principales objeciones que se hacían a san Fermín, Sala recurre a un paralelismo explícito con Santiago como patrón de España. Tampoco existía de él un documento de su elección ni de su canonización, ambas indudables. Le resulta impensable que el reino hubiera estado tanto tiempo «sin patrón de quien se pudiera valer ante el tribunal de Dios para el remedio de sus necesidades». Santiago era "patrón de España por tradición», y san Fermín lo era de Navarra del mismo modo. Además, cuando Pamplona celebra su fiesta no lo hace ella sola y por sí misma, sino «en nombre de todos los del reino» y en representación de Navarra entera. Tampoco España hace fiesta a Santiago, «y con todo esto lo tiene por patrón suyo»; porque, como ciudad cabeza del reino, no celebra los «regocijos» o los «sentimientos» de la familia real como reyes de Pamplona, sino como reyes de Navarra. E, insiste mucho, «los reyes [antiguos] tomaban la denominación de Pamplona por Navarra», y «las partes se incluyen en el todo, y los miembros en la cabeza». Finalmente, compara los méritos sobresalientes de san Fermín en Navarra con los de Santiago en España: «nos sacó de la idolatría y ciega gentilidad», y «nos ha conservado en su santa fe con tanta firmeza $\rangle^{77}$.

El punto tercero lo dedica a refutar que la elección y el voto o juramento de las cortes en favor de san Francisco Javier en 1624 hubiera sido legítimo y válido. Los Tres Estados se habrían extralimitado al tratar un asunto tan extraordinario sin que los procuradores de las universidades tuvieran poderes especiales y específicos; y, por otra parte, la autoridad del obispo no habría sancionado la obligatoriedad de tal voto espiritual. Si Urbano VIII había dispuesto (1642) que se celebrara con fiesta de precepto y con octava sólo a un santo patrón en cada comunidad, los breviarios antiguos demostraban que así se había hecho desde antiguo con san Fermín en todo el obispado, y que los últimos obispos no habían querido instituirlo de otra manera ${ }^{78}$.

La Diputación confió en la Compañía de Jesús la defensa de san Francisco Javier en el pleito del patronato, pero no promovió la publicación de textos alternativos a los de Urdániz (1648) y Salas (1650), o a la reedición del libro de Andueza (1656). Quizás porque había buenas biografías de este gran santo, aunque gestadas fuera, por y para extranjeros. Y, sobre todo, porque todavía

\footnotetext{
${ }^{76}$ SALA, 1650, «Punto segundo»: n. ${ }^{\circ}$ 14-26.

77 SALA, 1650, «Punto segundo»: n. ${ }^{\circ}$ 27-34.

78 SALA, 1650, «Punto tercero»: n. ${ }^{\circ} 35-51$.
} 
nadie había navarrizado su figura: no había reliquias suyas en el reino, ni se le atribuían grandes favores o apariciones, o la defensa de la comunidad ante las epidemias o la guerra, de la manera que se hacía con san Fermín. Por eso, los materiales que recogieron los jesuitas del Colegio de la Anunciada de Pamplona, aunque de superior calidad científico-histórica, sirvieron para negar las afirmaciones de los rivales, pero no pudieron erosionar una imagen popular bien asentada, ni intentaron adaptar la figura del jesuita a la realidad de su tierra natal.

Vida del glorioso San Fermín es el título facticio de un códice que reúne textos muy variados ${ }^{79}$. Comienza con una recopilación de fragmentos de breviarios y libros litúrgicos, martirologios, historias eclesiásticas y otras crónicas, sobre san Fermín y san Saturnino que, en conjunto, niegan de forma crítica los tres axiomas que reiteraban los «ferministas»: que san Fermín fuera el primer obispo de Pamplona, que evangelizara Navarra, y que fuese mártir de la iglesia primitiva. No sabemos quién los reunió, pero los jesuitas de Pamplona pudieron contar con colaboradores relevantes de indudable calidad científica por toda Europa. Entre ellos destaca Jean Bolland y su grupo de cooperadores, que firmó en Amberes en 1654 un De Firmino Episcopo Ambianensi Martyre. Commentarius previus, que se transcribe en el códice ${ }^{80}$. También hay un largo resumen de las posturas críticas, en Francia, sobre san Dionisio como primer evangelizador, que entendían como una mistificación equiparable a la de san Fermín en Navarra. Finaliza el códice con una Vida de San Fermín mártir, primer obispo de Amiens. Por M. Andrés del Val, traducción del francés de una biografía que se publicó en 1648 en una Historia Sanctorum Patris. En ella, el santo pierde toda relación con Navarra: sus padres ya eran cristianos antes que él y procedían de Nimes (Languedoc); y aunque hubiera nacido en Pamplona, habían confiado su catequización a san Honesto, en Toulouse, que lo ordenó obispo allí y lo envió, de inmediato, «pasar a la Galia llena toda de idolatría» ${ }^{81}$.

Los jesuitas acumularon autoridades que contradijeran «la parte adversa, id est el licenciado Urdániz». Primero, que «el glorioso san Fermín no plantó la fe en el dicho reino de Navarra ni ciudad de Pamplona»; segundo, que «no es ni ha sido condecorado con el título de Apóstol del reino de Navarra y ciudad de Pamplona»; tercero, que «no fue el primer obispo de esta ciudad y obispado de Pamplona»; cuarto, que «no sólo no fue primer obispo [...], más empero ni obispo de dicha ciudad y obispado»; quinto, que «no fue santo de la primitiva iglesia, id est del primero ni segundo século»; y sexto, que «no por eso, ipso iure, debe ser patrón de dicho reino [...] por faltarle como le falta al glorioso

79 Vida del glorioso San Fermín, AHN, Códices, n. 1290.

${ }^{80}$ MACEDA, 1798: 277-306.

81 Vida del glorioso San Fermín, AHN, Códices, n. ${ }^{\circ}$ 1290, ff. 1r-47v. Bolland: ff. 48r-73v. San Dionis: ff. 76r-83v. M. Andrés del Val: ff. 84v-86r. 
san Fermín la elección y nominación $»^{82}$. A mediados del siglo XVII, la más moderna crítica historiográfica en Europa estaba de acuerdo con quienes dudaban o desautorizaban a san Fermín con el mismo tipo de sospecha que se imponía en Francia a propósito de san Dionisio ${ }^{83}$. Y esta suspicacia general era compartida en Roma, pero ni mucho menos en Pamplona o por los navarros.

El punto más sólido del argumentario jesuítico, desde la perspectiva de los «ferministas» del momento, era el más innegable: que los Tres Estados de Navarra habían jurado como patrón a san Francisco Javier en 1624, y que otros reinos habían tenido la misma libertad de elegir, y que no siempre habían optado por el primer obispo, o por el primer evangelizador del país, y que no lo habían hecho en fechas antiguas sino muy recientes. Así ocurría en Guipúzcoa, «que recibió la luz del evangelio desde que la predicó el apóstol Santiago», lo mismo que Navarra, y que sin embargo había elegido por su patrón a san Ignacio de Loyola ese mismo año de 1624. O en Portugal, donde no hubo patrón del reino hasta que las Cortes de 1644 decidieron «recibir y jurar [...] por su patrona a la Santísima Virgen Nuestra Señora de la Concepción»; la capital, Lisboa, veneraba como tal a san Antonio de Padua, que «ni fue su primer obispo, ni en ella ni en parte del reino plantó la fe, ni aun predicó el evangelio». Y lo mismo ocurría en los reinos de la Corona de Aragón que,

... no obstante que tienen por patrón al apóstol Santiago, que lo es de toda España, tienen patrón principal a san Jorge, mártir de Capadocia, que ni es natural de ninguno de dichos reinos, ni ha sido condecorado con el título de primer apóstol, ni en ellos ni en parte alguna de ellos plantó la fe ${ }^{84}$.

Por otra parte, los patronos de Barcelona, Valencia y Zaragoza no eran, en ningún caso, sus primeros obispos. En definitiva, reiteran los «javieristas», la «elección de patrón de un reino, provincia, ciudad, etc., es acto libre, hiciéronla cómo y cuando gustaron, y en santo moderno».

\section{La concordia formal y el equilibrio real. ¿Copatronos o triunfo de san Fermín?}

El pleito sobre el patronato permaneció más de siete años estancado en Roma, entre la Congregación de Ritos y el Tribunal de la Rota, en torno a la duda sobre quién había sido válidamente elegido, y si este era «el patrón más principal». Los jesuitas descalificaban a san Fermín porque no había escrituras antiguas que lo

${ }^{82}$ Vida del glorioso San Fermín, AHN, Códices, n. ${ }^{\circ}$ 1290, ff. 14r, 20r, 22r, 26r, 32r, 38r. ARRAIZA, 2002: 68-72.

${ }^{83}$ LE GALL, 2007.

${ }^{84}$ Vida del glorioso San Fermín, AHN, Códices, n. . 1290, ff. 38v-40r. 
avalaran como patrón y porque nunca había sido rezado por tal en todos los pueblos del reino. Pamplona y el cabildo, por el contrario, subrayaban sus ventajas con respecto a san Francisco Javier: era un mártir (frente a un confesor), había beneficiado al reino con la fe y su protección (frente a quien no se le reconocían beneficios generales), era un santo antiguo (y no reciente), su patronato tenía antiguo arraigo popular (y no procedía de una elección precipitada $)^{85}$.

Todo ello agravó una situación política de tensiones antiguas, quizás más institucionales que populares, sobre todo en torno a Pamplona, que los virreyes veían como disfuncional, si no peligrosa, en tiempos de guerra. El duque de Escalona (1649-1653) se dirigió a las Cortes de 1652-1654 «en orden a la composición del pleito del patronato». Le preocupaban «la quietud de los vecinos de esta ciudad y muchos del reino» y los «disgustos y gastos» del pleito, además del escándalo religioso, y pretendía que la Diputación «conform[ase] con su primera y más principal ciudad», después de varios graves encontronazos que, por otra parte, estaban retrasando el servicio al rey en aquella reunión de cortes ${ }^{86}$. Y lo mismo hizo su sucesor, el conde de Santisteban (1653-1660), promoviendo una solución concertada que nunca se perdió de vista. Las relaciones entre el Consejo Real y la ciudad con ocasión, otra vez, de una corrida de toros en las ferias de San Fermín de 1653, estaban «en total rompimiento» cuando él llegó, afirmaba Santisteban, y también le preocupaba un ambiente popular crispado. Aunque pudiera exagerar, su despacho al Consejo de Estado, cuando ya se había alcanzado un acuerdo pacificador, es muy explícito sobre los «muchos inconvenientes» de desunión e indisciplina que el pleito sobre el patronato había favorecido:

... principalmente por la pasión de la gente popular, que tomaba pretexto de estas diferencias para abanderizarse y perder el respeto a la justicia y a los tribunales reales, de que ha habido continuas demostraciones, demás de la inobediencia con que se mostraron el año de 1653 corriendo los toros sin embargo de la orden de este Consejo, porque los dilatasen un día más por ser aquel de acuerdo, y antes después obraron otras acciones escandalosas ${ }^{87}$.

E hizo gestiones en la corte para doblegar la resistencia de «algunos prebendados de esta catedral» que no aceptaban la concordia, y escribió al prior y cabildo para evitar «los motivos de disconformidad y escándalo que con facilidad suelen experimentarse aquí $\rangle^{88}$.

${ }^{85}$ GOÑI, 1987, vol. VI: 150-177.

${ }^{86}$ Actas de Cortes de Navarra, libro 3, n. 900 (Pamplona, 12 de noviembre de 1652) y n. 911,912 y 1223 (1652-1653).

${ }^{87}$ Despacho del virrey de Navarra al Consejo de Estado (Pamplona, 2 de marzo de 1656), AHN, Estado, leg. 732, exp. 47.

${ }^{88}$ Despacho del virrey de Navarra al Consejo de Estado (Pamplona, 6 de julio de 1656), AHN, Estado, leg. 732, exp. 47. 
La transacción consistió en que el reino y la ciudad acordaron suplicar en Roma que san Fermín y san Francisco Javier fueran patronos «igualmente principales», que las fiestas de ambos fueran de precepto y que, en caso de concurrir, el primero prefiriera al segundo por ser mártir (13 de marzo de 1656). Y el papa Alejandro VII, considerando que las partes no habían demostrado su pretensión particular, sin aludir a la concordia previa y como si todo fuera de su iniciativa, para tranquilidad pública y salvación de las almas, concedió la dispensa para rezar a ambos «con rezo doble de primera clase con octava» por ser «aeque patroni principales» (14 abril 1657).

Parece más razonable pensar que la concordia respondió a un consenso amplio y sincero que lo contrario. Aunque un anónimo interpretó el acuerdo como resultado de una maniobra artera de los jesuitas que, como tenían peores argumentos, habrían forzado con mentiras, desde Roma, una concordia que el clero y el pueblo de Pamplona no querían. Porque no era cierto que el pueblo se hubiera banderizado por esta causa, ni que la paz espiritual de los navarros estuviera a riesgo de perderse, aunque fueran mayoría los que habían impugnado siempre la pretensión de los jesuitas. En cualquier caso, la realidad es que las fiestas de publicación del breve papal fueron tan extraordinarias en todas sus expresiones, con una tan amplia participación institucional y popular, que se impone la idea de una convergencia amplia y duradera de los navarros en torno al acuerdo de copatronato ${ }^{89}$.

Ahora bien, el acuerdo legal no frenó un desarrollo desequilibrado de las devociones populares en la segunda mitad del siglo XVII en favor de san Fermín y por encima de san Francisco Javier. Como en la otra gran polémica sobre patronato colectivo en el reino de Castilla, entre santa Teresa y Santiago (1618, 16261629), se mezclaron cuestiones religiosas, jurídico-políticas, intereses sociales, económicos, políticos y hasta personales, aunque en situaciones diversas.

Los reyes Felipe III y Felipe IV promovieron a santa Teresa como copatrona, junto con Santiago, y la introdujeron ante las Cortes de Castilla, quizás por devoción personal. También es cierto que, en varios sentidos, a principios del siglo XVII, Santiago «matamoros» no se ajustaba tanto a una nueva política más pacifista de la monarquía, y que había un agotamiento evidente de su devoción (peregrinaciones) y una fuerte contestación campesina al pago del «voto» a Santiago. En Navarra, fue la Diputación la que se adelantó a proponer a san Francisco Javier y quien luego movilizó a los Tres Estados del reino desde dentro. Parece claro que el impulso, en este caso, vino de la familia y linaje del santo y de un sector del Brazo Militar muy ligado a la Compañía de Jesús. También es probable un cierto contagio del entusiasmo con que, simultáneamente, los guipuzcoanos proclamaran a san Ignacio de Loyola como su patrón. Aunque objeto de importantes debates historiográficos, como es bien sabido,

${ }^{89}$ GOÑI, 1987, vol VI: 174-177.

Hispania, 2020, vol. LXXX, n. ${ }^{\circ}$ 266, septiembre-diciembre, págs. 817-850, ISSN: 0018-2141, e-ISSN: 1988-8368 https://oi.org/10.3989/hispania.2020.022 
Santiago era en Castilla una figura demasiado relevante y tradicional como para no contar con buenos defensores, y en pocos meses se desistió de seguir adelante con el proyecto de adjuntarle como copatrona a santa Teresa. La cuestión no volvió a plantearse hasta 1812 , en un contexto muy diferente ${ }^{90}$. San Fermín, que había cobrado su fuerza en el siglo XVI, sobre todo en las décadas finales, no era tan indiscutible y tardó en recibir el apoyo decidido de Pamplona y de su cabildo catedralicio, por lo que el enfrentamiento entre la ciudad y el reino se mantuvo latente (1622-1648) hasta estallar de forma abierta (16481657). El debate, por tanto, se desarrolló durante más tiempo y, quizás, con un cierto equilibrio entre los contendientes, lo que fraccionó a la sociedad y a las corporaciones de un modo que alarmó a los virreyes, dadas las circunstancias de guerra con Francia en aquel reino fronterizo.

Con ocasión de todos estos debates, los navarros pudieron confrontar e identificarse con dos modelos diferentes, si no contrapuestos, de santidad. San Fermín aludía a la antigüedad de la fe y a la primacía de su iglesia sobre otras posteriores y dependientes, en particular la de Francia, donde habría misionado y donde murió mártir; también refería a la autoridad episcopal y al clero diocesano, y a la preeminencia de Pamplona como cabeza y síntesis del reino. San Francisco Javier representaba algo diferente: el esfuerzo misionero ultramarino de la iglesia reformada en Trento, y la urgencia de la evangelización de todo el orbe a impulsos de una monarquía que se definía, precisamente, como católica; la vitalidad de una orden religiosa que, como otras, trabajaban en la vanguardia de la recuperación de Europa para el catolicismo romano; y, en último extremo, también recordaba que no todo lo grandioso tenía por qué ocurrir en Pamplona.

Inicialmente, el santo más tradicional (aunque no lo fuese en sentido estricto) se impuso al más moderno entre los navarros de dentro y de fuera del reino, por mucho que sean frecuentes las esculturas, las pinturas y, sobre todo, los grabados en que ambos copatronos son representados conjuntamente, haciendo pendant. La iconografía de san Fermín era muy reciente (s. XV) y sencilla, predominando la episcopal y martirial (capa y mitra rojas, báculo, pectoral y anillo, rostro juvenil, en actitud de bendecir). La de san Francisco Javier como predicador y evangelizador ha resultado, a la postre, más rica en la selección de ciertos pasajes de su vida, aunque predomine como figura erguida, con el crucifijo o una vara de azucenas, vistiendo la sotana jesuita o con roquete y estola. Una pintura encargada por el ayuntamiento de Pamplona en 1657 los presenta al lado de sendos escudos de Pamplona y de Navarra. Sin embargo, en los grabados que sirvieron de portada para las Investigaciones historicas de las antiguedades del reyno de Navarra (1665), y los Annales del reyno de Navarra (1684), del jesuita José de Moret, sólo aparece el escudo del

${ }^{90}$ REY, 67/136 (Madrid, 2015): 531-573; 1985. 
Figura 1. San Fermín y san Francisco de Javier, copatronos de Navarra, por Juan Andrés de Armendáriz en 1657 (Ayuntamiento de Pamplona)

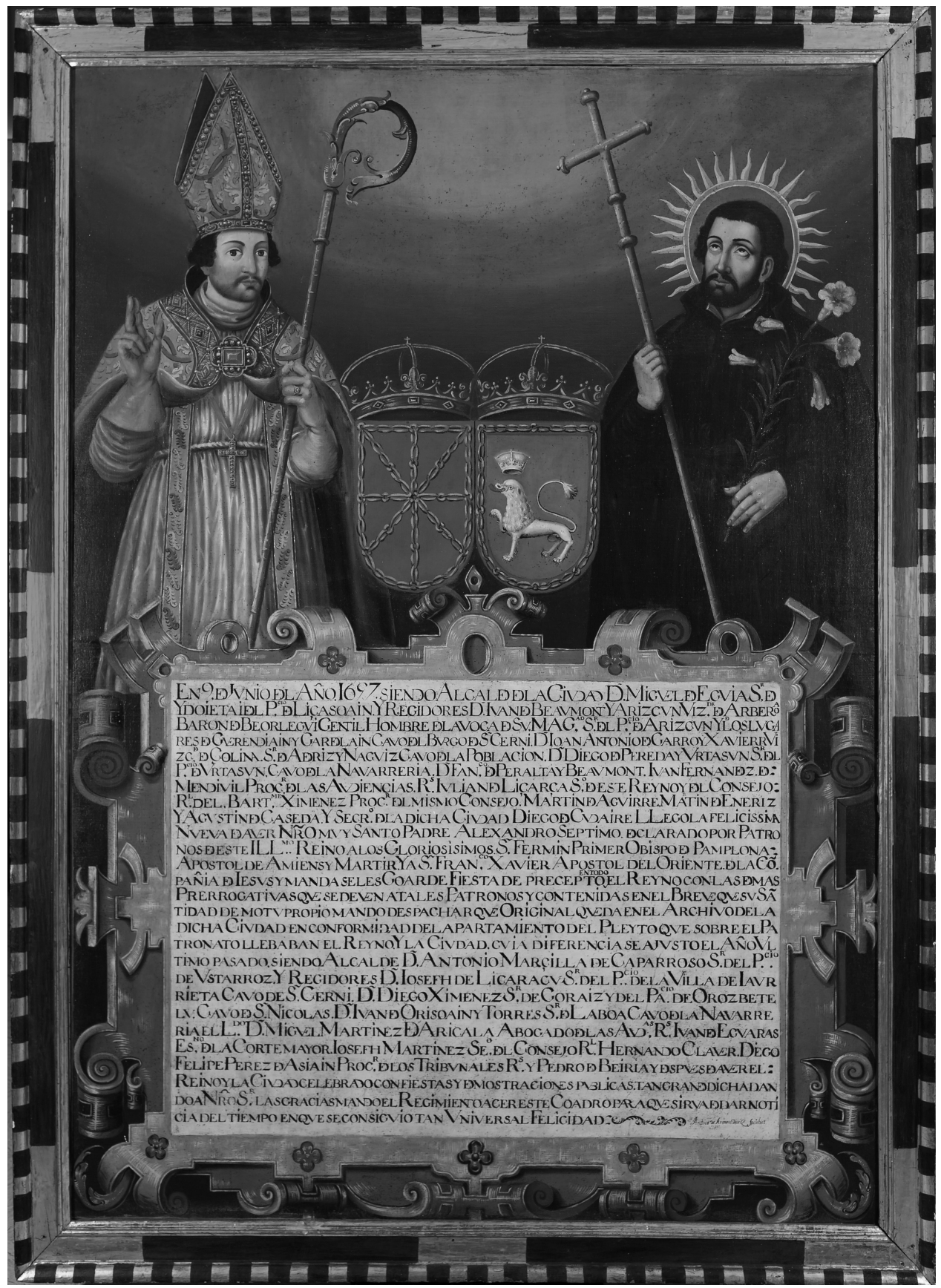

Hispania, 2020, vol. LXXX, n. ${ }^{\circ}$ 266, septiembre-diciembre, págs. 817-850, ISSN: 0018-2141, e-ISSN: 1988-8368 https://doi.org/10.3989/hispania.2020.022 
reino, y ya no el de la ciudad, entre ambos santos ${ }^{91}$. Ahora bien, la aceptación papal como patronos «igualmente principales» (1657) resultó más aparente que real, del mismo modo que el reconocimiento de la «unión principal» de Navarra a Castilla por Felipe IV (1652) no suponía equiparación perfecta sino, más bien, asimetría equilibrada.

En 1679, este mismo José de Moret reelaboró, por encargo de Pamplona, el oficio litúrgico de san Fermín en un latín más cuidado, pero manteniéndose fiel a los breviarios y misales que se conocían. Reescribió antífonas, himnos y prefacios, y el obispo Pedro Roche solicitó en Roma que se extendiera su rezo a toda España, contando con el apoyo conjunto de la Diputación y de Pamplona, pero, después de muchas gestiones, nunca se consiguió. Seguramente, porque la historicidad de san Fermín ya era tenida por muy endeble, en un tiempo en que la iglesia había empezado a depurar con energía los excesos de la hagiografía barroca, confrontándolos con una crítica documental de mayor rigor hermenéutico. Los mismos jesuitas pamploneses habían aportado demasiados materiales, durante los años del pleito por el patronato, en contra de san Fermín ${ }^{92}$. Y, sin embargo, todavía en 1798 la ciudad costeó con generosidad la publicación del libro del jesuita pamplonés Miguel José de Maceda, expulsado y refugiado en Italia. Sus Actas sinceras, nuevamente descubiertas, de los santos Saturnino, Honesto y Fermín, apóstoles de la antigua Vasconia (hoy Navarra y sus vecindades), pretendían haber encontrado en la Biblioteca Ricardiana de Florencia unas actas que probaban la evangelización de Pamplona y de Navarra ya en el siglo I, en contra de lo que la crítica moderna llevaba sosteniendo durante más de un siglo. La ciudad pagó la edición de un gran número de ejemplares de esta obra para mayor gloria de san Fermín y de san Saturnino.

En 1683, los navarros más influyentes en la corte pusieron su cofradía nacional bajo el amparo de san Fermín. El Convento de la Victoria, de religiosos mínimos de San Francisco de Paula, en Madrid, se preciaba de conservar en una de sus capillas una cabeza de san Fermín como reliquia, obsequio de Isabel de Valois, según el cronista de la orden (1619). Quizás en torno a ella se reuniera, más temprano de lo que pensábamos, la nación navarra en la corte. En 1649, Miguel de Urdániz se refería al contraste entre la devoción a san Fermín «en los hijos de V.S. [Pamplona], algo de lo antiguo resfriada [...], al paso que crece en los de afuera del reino ${ }^{93}$. En la introducción de las primitivas constituciones, los nuevos congregantes se referían a que, «por la sucesiva herencia de muchos siglos [...], ha crecido la devoción de los navarros a su gran patrón y padre san Fermín», por lo que decidieron «consagrarle

\footnotetext{
91 FERNÁNDEZ, 2006: 227-296. ARRAIZA, 2002: 121-126.

${ }_{92}$ GOÑI, 1987, vol. VI: 371-373. ARRAIZA, 2002: 157-159.

93 URDÁNIZ, 1649: Cuarto discurso, sin paginar.
} 
en públicos y perpetuos cultos como a patrón y valedor», estableciendo esta nueva Real Congregación Nacional (1683) ${ }^{94}$.

Por último, en 1696 el regimiento de Pamplona acordó levantar una nueva capilla a san Fermín en la parroquia de San Lorenzo, para lo que promovió una gran ampliación del templo, terminada en 1717, que duplicó su superficie. La ciudad costeó buena parte de la obra y quedó como patrón de la capilla, que es el lugar que ha centrado el culto a san Fermín hasta hoy. Aunque parte del dinero lo aportaron navarros que residían en «Madrid y en los puertos de Santa María, Sevilla y Cádiz, como también en los reinos de Indias de la Nueva España, y algunos indianos que residen en este reino»» ${ }^{95}$.

San Francisco Javier, por sus propias dimensiones, se ha convertido en una de las grandes figuras de la iglesia universal, pero sólo desde finales del siglo XIX, en un determinado contexto de cambio cultural, ha constituido también un referente particular para la identidad colectiva de los navarros ${ }^{96}$. De hecho, su festividad alberga hoy el «día de Navarra» en nuestra autonomía y es festivo para todos, mientras que el día de San Fermín lo es sólo en Pamplona. En cualquier caso, parece claro que los «sanfermines», muy conocidos fuera, y las «javieradas», más vividas dentro, han contribuido también, de otra manera, a sucesivas reelaboraciones de la identidad colectiva de los navarros incluso en el siglo $\mathrm{XX}^{97}$.

\section{Bibliografía}

Actas de las Cortes de Navarra (1530-1829). Edición de L. J. Fortún Pérez de Ciriza, Pamplona, Parlamento de Navarra, 1991-1995, 19 tomos.

Actas de las Juntas Generales de Álava, disponibles en: http://www.jjggalava.eus/ActasHistoricas/?lang=es

Aleson, Francisco, Annales del Reyno de Navarra, compuestos por el P. Francisco de Aleson, de la Compañía de Jesús, chronista del mismo reyno, Pamplona, 1707, tomo IV.

Andueza, Ignacio de, Vida y martirio de los santos patronos de la ciudad de Pamplona San Saturnino y San Fermín, con tres discursos breves de la cruz, del martirio y de otras particularidades antiguas, Pamplona, Gaspar Martínez, 1656 [1. ed. 1607].

Anguera, Pere, Sant Jordi: patró de Catalunya, Barcelona, Rafael Dalmau, 2010.

Arraiza Frauca, Jesús, San Fermín. El santo, la devoción, la fiesta, Pamplona, Ayuntamiento de Pamplona, 2002.

\footnotetext{
94 SAGÜÉS, 1963: 27-30. GARCÍA GAÍNZA, 1997: 187-196.

95 GARCÍA GAIINZA, 1997: 187-190.

${ }^{96}$ LEONÉ, 2002: 33-120.

${ }^{97}$ BERIAIN, 1998: 85-102.
} 
Beriáin, Josetxo, La identidad colectiva: vascos y navarros, Pamplona, Universidad Pública de Navarra, 1998.

Canellas López, Ángel, «Leyenda, culto y patronazgo en Aragón del señor San Jorge, mártir y caballero», Cuadernos de Historia Jerónimo Zurita, 19-20 (Zaragoza, 1966-1967): 7-22.

Christian, William A., Religiosidad local en la España de Felipe II, Madrid, Nerea, 1991 [1. ${ }^{\circ}$ ed. Princeton, University Press, 1981].

Constituciones synodales del obispado de Pamplona. Copiladas, hechas y ordenadas por don Bernardo de Rojas y Sandoval [...] en la synodo que se celebro en su Iglesia Cathedral de la dicha ciudad el mes de agosto de MDXC años, Pamplona, Thomas Porralis, 1991.

Dubois, J., «Saint Firmin», en Alfred Baudrillart, Dictionnaire d'histoire et de géographie ecclésiastiques, París, Latouzay et Ané, 1971, vol. X: 252-257.

El sacrosanto y ecuménico concilio de Trento, traducido al idioma castellano por D. Ignacio López de Ayala, con el texto latino corregido según la edición auténtica de Roma publicada en 1564, Barcelona, Imp. R. Martín, 1847.

Fernández Gracia, Ricardo, San Francisco Javier Patrono de Navarra. Fiesta, religiosidad e iconografía, Pamplona, Gobierno de Navarra, 2006.

Ferrer García, Félix A., «Felipe II y la conquista de reliquias por los tercios de Flandes: el ejemplo de Leyden (1570-1574)», Hispania Sacra, LXVI (Madrid, 2014): 67-95.

Floristán Imízcoz, Alfredo, Lealtad y patriotismo tras la conquista de Navarra. El licenciado Reta y la «Sumaria relación de los apellidos», Pamplona, Gobierno de Navarra, 1999.

Floristán Imízcoz, Alfredo, «“Ex hostibus et in hostes”. La configuración de identidades colectivas como confrontación múltiple: Navarra entre Sobrarbe y Cantabria (siglos XVI y XVII)», en Antonio Álvarez-Ossorio y Bernardo J. García (eds.), La Monarquía de las naciones. Patria, nación y naturaleza en la Monarquía de España, Madrid, Fundación Carlos de Amberes, 2004: 327-354.

García Gaínza, M. ${ }^{a}$ Concepción (dir.), Catálogo monumental de Navarra, Pamplona, Gobierno de Navarra/Arzobispado de Pamplona/Universidad de Navarra, 1997, vol. V.

Gómez Zorraquino, José Ignacio, «Los santos patronos y la identidad de las comunidades locales en la España de los siglos XVI-XVII», en Eliseo Serrano (ed.), Fábrica de santos: España, siglos XVI-XVII, dossier de la revista Jerónimo Zurita, 85 (Zaragoza, 2010): 39-74.

Goñi Gaztambide, José, Historia de los obispos de Pamplona, Pamplona, Eunsa/ Diputación Foral de Navarra, 1979 (vol. I), 1985 (vol. IV), 1987 (vols. V y VI).

Jimeno Aranguren, Roldán, El culto a los santos en la Cuenca de Pamplona (siglos $V$-XVI). Estratigrafía hagionímica de los espacios sagrados urbanos y rurales, Pamplona, Gobierno de Navarra, 2003.

Le Gall, J. M., Le mythe de Saint Denis entre Renaissance et Révolution, París, Champ Vallon, 2007.

Leoné Puncel, Santiago, Los lugares de la memoria en Navarra, tesis doctoral inédita, Universidad de Navarra, 2002.

Maceda, Miguel Joseph de, Actas sinceras nuevamente descubiertas de los santos Saturnino, Honesto y Fermín, apóstoles de la antigua Vasconia (hoy Navarra y 
sus vecindades) por las cuales se pone en claro el tiempo en que florecieron, y el obispado de San Fermín. Las da a luz, las defiende y las dirige a su patria Pamplona, Madrid, Imprenta Real, 1798.

Maravall, Pierre (ed.), Actes et Passions des martyrs chrétiens des premiers siècles (introducción, traducción y notas de Pierre Maravall), París, Ed. du Cerf, 2010.

Marco Simón, Francisco, El Señor San Jorge: patrón de Aragón, Zaragoza, Caja de Ahorros de la Inmaculada de Aragón, 1999.

Marques, Joao Francisco, «A tutela do sagrado: a proteção dos santos padroeiros no periodo da Restauração», en Francisco Bethencourt y Diego Ramada Curto (eds.), A memória da nação, Lisboa, Livraria Sá da Costa, 1991: 267-294.

Márquez Villanueva, Francisco, Santiago: trayectoria de un mito, Barcelona, Bellaterra, 2004.

Núñez de Cepeda, Marcelo, Los votos seculares de la ciudad de Pamplona, Pamplona, Aramburu, 1942.

Orcástegui Gros, Carmen, La crónica de los reyes de Navarra del Príncipe de Viana (estudio, fuentes y edición crítica), Pamplona, Diputación Foral de Navarra, 1978.

Pérez Goyena, Antonio, La santidad en Navarra, Pamplona, Seminario Diocesano de Pamplona, 1947.

Rey Castelao, Ofelia, La historiografía del Voto de Santiago: recopilación crítica de una polémica histórica, Santiago de Compostela, Universidad de Santiago de Compostela, 1985.

Rey Castelao, Ofelia, «La disputa del patronazgo de la Monarquía: ¿Santiago o Santa Teresa?», en José Martínez Millán (coord.), La monarquía de Felipe III, Madrid, Mapfre, 2008, vol. 1: 227-245.

Rey Castelao, Ofelia, «Teresa, patrona de España», Hispania sacra, 67/136 (Madrid, 2015): 531-573.

Rodríguez, Pedro y Rodríguez, Justina, Don Francés de Alava y Beamonte. Correspondencia inédita de Felipe II con su embajador en París (1564-1570), San Sebastián, Caja Gipuzkoa, 1991.

Rowe, Erin K., Saint and Nation: Santiago, Teresa of Avila and plural identities in early modern Spain, University Park, The Pennsylvania State University Press, 2011.

Sagüés Azcona, Pío, La Real Congregación de San Fermín de los Navarros en Madrid (1683-1961), Madrid, Gráficas Canales, 1963.

Sala, Juan de la, Razones y autoridades con se prueva que San Fermín es el patrono más principal del Reyno de Navarra, Pamplona, Martín de Labayen y Diego de Zabala, 1650.

Sandoval, Prudencio de, Catálogo de los obispos que ha tenido la Santa Iglesia de Pamplona, Pamplona, Nicolás de Asiayn, 1614.

Serrano Martín, Eliseo, El Pilar, la historia y la tradición: la obra erudita de Luis Diez de Aux (1562-ca. 1630), Zaragoza, Mira, 2014.

Serrano Martín, Eliseo, «"Silentium facite”: El fin de la polémica y el discurso en torno a la Virgen del Pilar en la Edad Moderna», Hispania, LXXIV (Madrid, 2014): 687-714.

Serrano Martín, Eliseo, «Hagiografía y milagro: fabricar santos en la Edad Moderna», en José Luis Moya (ed.), Identidades y fronteras culturales en el mundo ibérico en la Edad Moderna, Barcelona, Universidad Autónoma de Barcelona, 2016: 193-216. 
Serrano Martín, Eliseo, «Santidad y patronazgo en el mundo hispánico de la Edad Moderna», Studia historica. Historia moderna, 40/1 (Salamanca, 2018): 75-123.

Serrano Martín, Eliseo, «Santos que quedaron en el camino: Vidas religiosas y procesos hacia la santidad en la Edad Moderna. Una aproximación con ejemplos aragoneses»,, en Inmaculada Arias de Saavedra (dir.), Subir a los altares: modelos de santidad en la Monarquía Hispánica (siglos XVI-XVIII), Granada, Universidad de Granada, 2018: 155-185.

Thompson, Irving A. A., "La cuestión de la autoridad en la controversia sobre el patronato de Santa Teresa de Jesús», en Francisco José Aranda y José Damião Rodrigues (eds.), De Re Publica Hispaniae. Una vindicación de la cultura política en los reinos ibéricos de la primera modernidad, Madrid, Sílex, 2008: 293-320.

Thompson, Irving A. A., «Santiago $v$ Santa Teresa- signifying what?», en Julio Pardos, Julen Viejo, José María Iñurritegui y Fernando de Andrés (eds.), Historia en fragmentos. Estudios en homenaje a Pablo Fernández Albaladejo, Madrid, UAM Ediciones, 2017: 413-422.

Urdániz, Miguel de, Memorial que se dio a la muy noble, antiquissima e imperial ciudad de Pamplona, cabeça del Ilustrissimo y Nobilissimo Reyno de Navara, en nombre del Cabildo Eclesiastico de la Iglesia Parroquial del señor S. Lorenzo de la misma ciudad, Pamplona, Martín de Labayen y Diego de Zabala, 1649.

Usunáriz Garayoa, Jesús M. , "Las instituciones del reino de Navarra durante la Edad Moderna (1512-1808)», Revista Internacional de Estudios Vascos, 46/2 (Donostia, 2001): 685-744.

Vincent-Cassy, Cécile, Les sants vierges et martyres dans l'Espagne du XVII siècle, Madrid, Casa de Velázquez, 2001.

Vincent-Cassy, Cécile, «Las fiestas de canonización en la España del siglo XVII, polifonía de la santidad monárquica», en Ángela Atienza (coord.), Iglesia memorable. Crónicas, historias, escritos...a mayor gloria. Siglos XVI-XVIII, Madrid, Silex, 2012a: 149-167.

Vincent-Cassy, Cécile, «Saint Michel et la monarchie hispanique. L'invocation de la protection angélique en 1643», en Florence Buttay y Axelle Guillausseau (dirs.), Des saints d'Etat? Politique et sainteté au temps du Concile de Trente, París, Université de Paris-Sorbonne, 2012b: 89-103.

Vincent-Cassy, Cécile y Civil, Pierre (eds.), Hacedores de santos. La fábrica de santidad en la Europa católica, siglos XV-XVIII, Madrid, Doce Calles, 2019.

Worcester, Thomas, «Saint as Cultural History», en Joan Pau Rubiés, Melisa Calaresu y Filippo de Vivo (eds.), Exploring Cultural History: Essays in Honour of Peter Burke, Farnham, Ashgate Publishing, 2010: 191-206.

Recibido: $11 / 06 / 2019$

Aceptado: 13/10/2020 